\title{
Asymmetric Synthesis of a Tertiary Arsine by Nucleophilic Addition to a Chiral Phosphine-Stabilized Arsenium Salt
}

\author{
Michelle L. Coote, Elizabeth H. Krenske, Keith A. Porter, Michelle L. Weir, \\ Anthony C. Willis, Xiangting Zhou, and S. Bruce Wild* \\ Research School of Chemistry, Institute of Advanced Studies, Australian National University, \\ Canberra, ACT 0200, Australia
}

Received July 4, 2008

\begin{abstract}
A new method for the asymmetric synthesis of $A s$-chiral tertiary arsines is described. The addition at $-95{ }^{\circ} \mathrm{C}$ of $n$-butyllithium to a dichloromethane solution of a phosphine-stabilized arsenium salt of the type $( \pm)-\left[\mathrm{R}_{3} \mathrm{P} \rightarrow \mathrm{AsMePh}\right] \mathrm{PF}_{6}$, where $\mathrm{R}_{3} \mathrm{P}$ is an enantiomerically pure, atropisomeric phosphepine derived from lithiated $(\mathrm{a} R)$-2,2'-dimethyl-1, $1^{\prime}$-binaphthalene, furnishes $\left(S_{\mathrm{As}}\right)-(+)-(n$-butyl)methylphenylarsine in $85 \%$ enantioselectivity (70\% enantiomeric excess) with displacement of the $\left(\mathrm{a} R_{\mathrm{P}}\right)$-phosphepine. The enantioselectivity of the synthesis is lower than the diastereoselectivity of coordination of the $\left(\mathrm{a} R_{\mathrm{P}}\right)$ phosphepine to the prochiral, six-electron methylphenylarsenium ion with which it is in equilibrium in solution by $\mathrm{P}-\mathrm{As}$ bond dissociation, $94 \%$ diastereomeric excess, as determined by NMR spectroscopy at $-95^{\circ} \mathrm{C}$. The excess of the $S$ enantiomer of the arsine, however, is consistent with the $\mathrm{S}_{\mathrm{N}} 2$ mechanism proposed for the reaction and the solution and solid-state structures of the predominant diastereomer of the phosphepine-arsenium complex. A feature of the design of the phosphepine auxiliary is the attachment of a 2-(methoxymethyl)phenyl substituent at phosphorus, the oxygen of which interacts with the arsenic of the arsenium ion, in solution and in the solid state, and facilitates stereodifferentiation by the chiral phosphepine of the enantiotopic faces of the prochiral, six-electron methylphenylarsenium ion; the significance of this anchimeric interaction is borne out by DFT calculations on a closely related model complex.
\end{abstract}

\section{Introduction}

Coordination chemistry has merged with organic and organometallic chemistry such that there are now modifications available for nearly every standard reaction for converting achiral organic substrates into chiral products. Together with modern purification techniques, this has allowed the preparation - in a single step - of compounds in $>98 \%$ enantiomeric purity by asymmetric catalysis for many reaction types. Although the pioneering developments in catalytic asymmetric synthesis involved the use of $P$-chiral monophosphines ${ }^{1}$ and related diphosphines $^{2}$ in Wilkinson-type rhodium-phosphine complexes, it soon became apparent that chelating bis(diphenylphosphines) containing configurationally pure backbones of $C_{2}$ symmetry gave equally good and often superior results because of the steric influence of the dissymmetric, edge-face array of the four phenyl groups on the adjacent phosphorus atoms in the catalysts. ${ }^{3}$ Nevertheless, there are applications where $P$-chiral monophosphines are superior to chelating diphosphines for

* Corresponding author. Fax: +61 26125 3216. Tel: +61 261254236. E-mail: sbw@rsc.anu.edu.au.

(1) (a) Horner, L.; Büthe, H.; Siegel, H. Tetrahedron Lett. 1968, 40234026. (b) Horner, L.; Siegel, H.; Büthe, H. Angew. Chem., Int. Ed. Engl. 1968, 7, 942. (c) Horner, L.; Siegel, H. Phosphorus Relat. Group V Elem. 1972, 1, 209-216. (d) Knowles, W. S.; Sabacky, M. J. J. Chem. Soc., Chem. Commun. 1968, 1445. (e) Knowles, W. S.; Sabacky, M. J.; Vineyard, B. D. J. Chem. Soc., Chem Commun. 1972, 10-11.

(2) Knowles, W. S.; Sabacky, M. J.; Vineyard, B. D.; Weinkauff, D. J. J. Am. Chem. Soc. 1975, 97, 2567-2568.

(3) (a) Dang, T. P.; Kagan, H. B. J. Chem. Soc., Chem. Commun. 1971, 481. (b) Dang, T.; Kagan, H. J. Am. Chem. Soc. 1972, 6429-6433. (c) Fryzuk, M. D.; Bosnich, B. J. Am. Chem. Soc. 1977, 99, 6262-6267. (d) Fryzuk, M. D.; Bosnich, B. J. Am. Chem. Soc. 1978, 100, 5491-5494. asymmetric synthesis. ${ }^{4}$ There are also examples of catalytic reactions where $A s$-chiral mono- and diarsines outperform the phosphorus isosteres. ${ }^{5}$ A drawback to the use of tertiary phosphines and arsines chiral at the donor stereocenters, however, has been the deficiency of convenient asymmetric syntheses for the ligands, ${ }^{4 b, 6}$ especially arsines, ${ }^{7}$ although the field has expanded enormously since the pioneering work that demonstrated that unsymmetrically substituted $(1 R, 2 S, 5 R)$ menthylphosphinates and $(1 R, 2 S, 5 R)$-menthylthioarsinates could be separated into diastereomers, epimeric at phosphorus or arsenic, that could be converted by Grignard or organolithium reagents into $P$-chiral tertiary phosphine oxides ${ }^{8}$ and $A s$-chiral tertiary arsines. ${ }^{9}$ There have also been asymmetric syntheses of $P$-chiral phosphines and $A s$-chiral arsines by electrophilic alkyl additions to phosphido- and arsenido-iron and -ruthenium complexes containing enantiomerically pure co-ligands, ${ }^{10}$ a significant new development based on this approach has been the catalytic asymmetric synthesis of a number of $P$-chiral

(4) (a) Lagasse, F.; Kagan, H. B. Chem. Pharm. Bull. 2000, 48, 315324. (b) Crépy, K. V. L.; Imamoto, T. Top. Curr. Chem. 2003, 229, 1-40.

(5) (a) Allen, D. G.; Wild, S. B.; Wood, D. L. Organometallics 1986, 5, 1009-1015. (b) Mokhlesur Rahman, A. F. M. M.; Wild, S. B. J. Mol. Catal. 1987, 39, 155-160. 1411

(6) Pietrusiewicz, K. M.; Zablocka, M. Chem. Rev. 1994, 94, 1375-

(7) Wild, S. B. In The Chemistry of Organic Arsenic, Antimony and Bismuth Compounds; Patai, S., Ed.; John Wiley and Sons: Chichester, 1994; Chapter 3.

(8) (a) Korpiun, O.; Mislow, K. J. Am. Chem. Soc. 1967, 89, 47844785. (b) Korpiun, O.; Lewis, R. A.; Chickos, J.; Mislow, K. J. Am. Chem. Soc. 1968, 90, 4842-4846. (c) Nudelman, A.; Cram, D. J. J. Am. Chem. Soc. 1968, 90, 3869-3870.

(9) Stackhouse, J.; Cook, R. J.; Mislow, K. J. Am. Chem. Soc. 1973, 95, 953-955. 
phosphines from secondary phosphines on divalent palladium, ${ }^{11}$ platinum, ${ }^{12}$ and ruthenium. ${ }^{13}$ Nevertheless, despite the limitation of $50 \%$ yield for the isolation of a particular enantiomer of a $P$-chiral phosphine or $A s$-chiral arsine by resolution, resolutions via the separation of the diastereomeric metal complexes containing chiral co-ligands remain necessary for the isolation of enantiomerically pure monotertiary $P$-chiral phosphines and As-chiral arsines, especially liquids, ${ }^{14}$ and new methods for the asymmetric synthesis of these important compounds in high enantioselectivity and chemical yield are required. Here we report the results of our work concerning the enantioselective synthesis of $(S)$-As $(n-\mathrm{Bu}) \mathrm{MePh},(S)-2,{ }^{15}$ by a novel approach involving the nucleophilic addition of an organolithium reagent to a phosphine-stabilized arsenium salt in which the phosphine is the configurationally stable atropisomer $\left(\mathrm{a} R_{\mathrm{P}}\right)-\mathbf{1}$.<smiles>COCc1ccccc1P1Cc2ccc3ccccc3c2C(c2cccc3ccccc23)C1</smiles>

$\left(\mathrm{a} R_{\mathrm{P}}\right)-1$

\section{Results and Discussion}

General Considerations and Methodology. Phosphinestabilized arsenium salts are generally air- and water-stable complexes and can be conveniently prepared by the reaction of a tertiary phosphine with an iododiorganoarsine in dichloromethane in the presence of an excess of ammonium or potassium hexafluorophosphate in water (eq 1). ${ }^{19 a}$

$$
\begin{aligned}
\mathrm{R}_{3} \mathrm{P}+\left|\mathrm{AsR}_{2} \underset{\mathrm{CH}_{2} \mathrm{Cl}_{2}}{\rightleftharpoons}\left[\mathrm{R}_{3} \mathrm{P} \rightarrow \mathrm{AsR}_{2}\right]\right| & \\
& \stackrel{\mathrm{MPF}_{6}}{\underset{\mathrm{H}_{2} \mathrm{O}}{\longrightarrow}}\left[\mathrm{R}_{3} \mathrm{P} \rightarrow \mathrm{AsR}_{2}\right] \mathrm{PF}_{6}
\end{aligned}
$$

Phosphine-arsenium complexes undergo rapid phosphine exchange, viz. $\Delta G^{\ddagger}(\mathrm{P}-\mathrm{As}$ bond dissociation $)=62 \mathrm{~kJ} \mathrm{~mol}^{-1}$ at $281 \mathrm{~K}$ for $\left[\mathrm{Ph}_{3} \mathrm{P} \rightarrow \mathrm{AsMePh}\right] \mathrm{PF}_{6}$ in dichloromethane- $d_{2}$, and have distorted pyramidal structures in the solid state in which the coordination geometry around the arsenic is based on the trigonal pyramid; the arsenic is at the center of the trigonal plane containing the two ipso carbon atoms of the organic groups and the lone pair of electrons of the six-electron $\mathrm{R}_{2} \mathrm{As}^{+}$group, and the phosphorus atom lies directly above the arsenic and is orthogonal to the trigonal plane at a distance of typically 2.3

(10) (a) Buhro, W. E.; Zwick, B. D.; Georgiou, S.; Hutchinson, J. P.; Gladysz, J. A. J. Am. Chem. Soc. 1988, 110, 2427-2439. (b) Crisp, G. T.; Salem, G.; Wild, S. B. Organometallics 1989, 8, 2360-2367. (c) Salem, G.; Wild, S. B. J. Organomet. Chem. 1989, 370, 33-41. (d) Bohle, D. S.; Clark, G. R.; Rickard, C. E. F.; Roper, W. R. J. Organomet. Chem. 1990, 393, 243-285.

(11) Moncarz, J. R.; Laritcheva, N. F.; Glueck, D. S. J. Am. Chem. Soc. 2002, 124, 13356-13357.

(12) Scriban, C.; Glueck, D. S. J. Am. Chem. Soc. 2006, 128, 27882789.

(13) Chan, V. S.; Stewart, I. C.; Bergman, R. G.; Toste, F. D. J. Am. Chem. Soc. 2006, 128, 2786-2787.

(14) Wild, S. B. Coord. Chem. Rev. 1997, 166, 291-311.

(15) The synthesis of $(+)$-As $(n-\mathrm{Bu}) \mathrm{MePh}$ was first achieved by the cathodic reduction at a mercury electrode of (+)-[AsBn( $n$ - $\mathrm{Bu})] \mathrm{MePh}] \mathrm{ClO}_{4}$ which occurs with retention of configuration at arsenic. ${ }^{16}$ The absolute configuration of $(+)$ - $[\mathrm{AsBnMePh}(n-\mathrm{Pr})] \mathrm{BPh}_{4}$ was subsequently established as $S$ by the quasi-racemate method of Fredga in conjunction with the dextarotatory phosphorus analogue ${ }^{17}$ and knowledge of the crystal structure of $(S)-(+)-[\mathrm{PBnMePh}(n-\mathrm{Pr})] \mathrm{Br}{ }^{18}$

(16) Horner, L.; Fuchs, H. Tetrahedron Lett. 1962, 203-204.
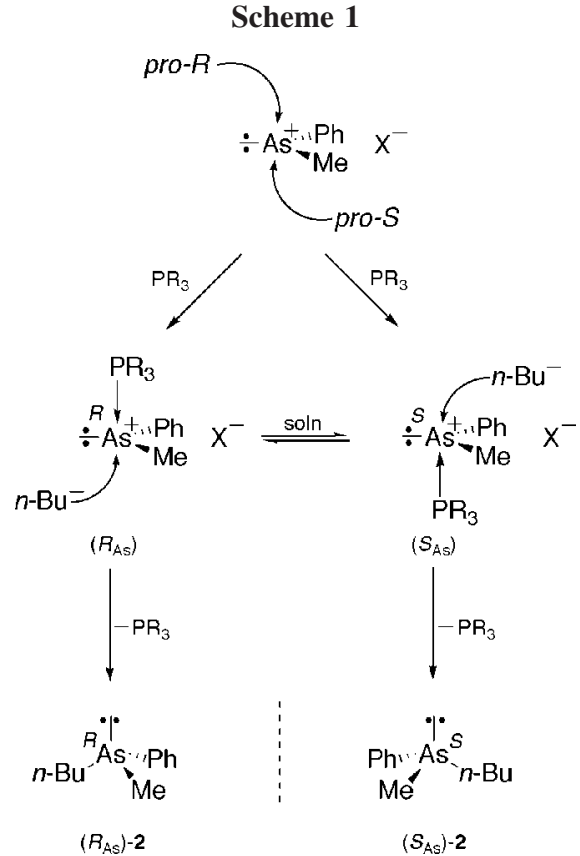

$\AA .{ }^{19}$ When the organic groups on the arsenic are different, the arsenium ion is prochiral and the addition of a phosphine to one or the other of the enantiotopic faces of the trigonal plane containing the angular $\mathrm{R}_{2} \mathrm{As}^{+}$ion generates the corresponding enantiomer of the phosphine-stabilized arsenium complex. The absolute configuration of an enantiomer of the chiral cation of the complex can be assigned by viewing the structure down the axis containing the ligand of lowest Cahn-Ingold-Prelog (CIP) priority (the lone pair, priority number 4) and observing the direction of rotation of the remaining ligands $1 \rightarrow 3$ at the corners of the triangular face at the base of the pyramid. ${ }^{20}$ Nucleophilic addition at arsenic in the cation $( \pm)-\left[\mathrm{R}_{3} \mathrm{P} \rightarrow\right.$ $\mathrm{AsMePh}]^{+}$by the carbanion $n-\mathrm{Bu}^{-}$will occur at the face opposite the phosphine to generate the respective enantiomer of configurationally stable $( \pm)-\mathrm{As}(n-\mathrm{Bu}) \mathrm{MePh},( \pm)-2,{ }^{21}$ with displacement of the phosphine (Scheme 1). Because of the lability of the $\mathrm{P}-\mathrm{As}$ bonds in complexes of the type $( \pm)$ $\left[\mathrm{R}_{3} \mathrm{P} \rightarrow \mathrm{AsMePh}_{\mathrm{P}} \mathrm{PF}_{6}\right.$, however, complexes in which the phosphine itself is chiral will exist in solution as an equilibrium mixture of two diastereomers, epimeric at the stereogenic arsenic center. The position of the equilibrium will depend upon the relative stabilities of the two diastereomers of the complex under the reaction conditions. If the phosphine is enantiomerically pure and the carbanionic reagent adds irreversibly to the phosphinestabilized arsenium centers of the equilibrating mixture of diastereomers at a rate that is faster than the rate of phosphine exchange between the diastereomers, the prevailing configuration of the product will correspond to the configuration of the

(17) Horner, L.; Winkler, H.; Meyer, E. Tetrahedron Lett. 1965, 789792.

(18) Peerdeman, A. F.; Holst, J. P. C.; Horner, L.; Winkler, H. Tetrahedron Lett. 1965, 811-815.

(19) (a) Porter, K. A.; Willis, A. C.; Zank, J.; Wild, S. B. Inorg. Chem. 2002, 41, 6380-6386. (b) Burford, N.; Ragogna, P. J.; Sharp, K.; McDonald, R.; Ferguson, M. J. Inorg. Chem. 2005, 44, 9453-9460.

(20) (a) Cahn, R. S.; Ingold, C. K.; Prelog, V. Angew. Chem., Int. Ed. Engl. 1966, 5, 385-415. (b) Eliel, E. L.; Wilen, S. H.; Mander, L. N. Stereochemistry of Organic Compounds; John Wiley and Sons, Inc.: New York, 1994.

(21) The free energy of activation, $\Delta G^{\ddagger}$, for the racemization of $(R)$ $(-)$ - and $(S)$ - $(+)$-ethylmethylphenylarsine has been calculated from kinetic data to be $175 \pm 2 \mathrm{~kJ} \mathrm{~mol}^{-1}$ at $217.6^{\circ} \mathrm{C} .^{22}$ 


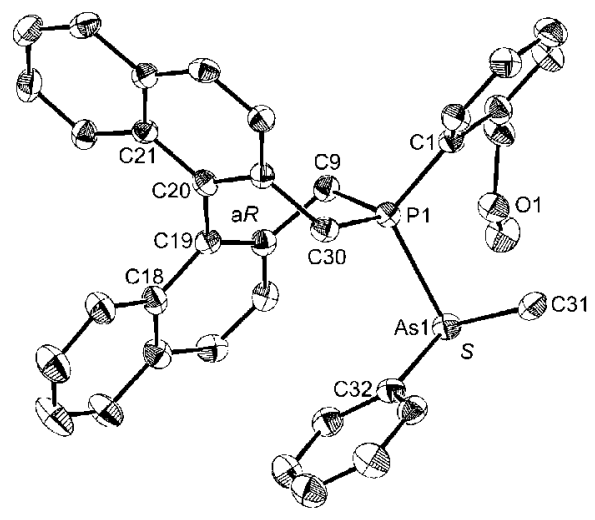

(a)

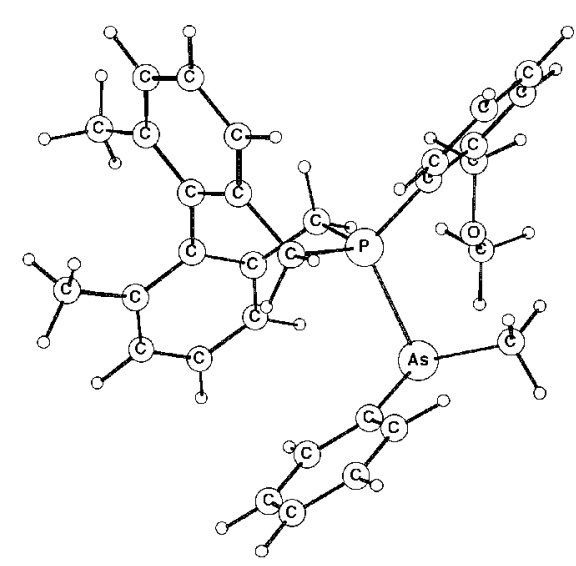

(b)

Figure 1. Observed structure of the cation of $\left(\mathrm{a} R_{\mathrm{P}}, S_{\mathrm{As}}\right)-[1 \rightarrow \mathrm{AsMePh}] \mathrm{PF}_{6} \cdot 0.26 \mathrm{CH}_{2} \mathrm{Cl}_{2} \cdot 0.37 \mathrm{Et}_{2} \mathrm{O}$ (a) and corresponding lowest-energy structure of $\left(\mathrm{a} R_{\mathrm{P}}, S_{\mathrm{As}}\right)-[6 \rightarrow \mathrm{AsMePh}]^{+}$obtained from the DFT calculations (b). Selected bond lengths $(\AA)$ and interbond angles (deg) in the crystal structure (ellipsoids show 30\% probability levels) and corresponding theoretical values in square brackets: As1-P1 = 2.3579(12) [2.430], $\mathrm{As} 1-\mathrm{C} 31=1.960(5)$ [1.993], As1-C32 = 1.954(5) [1.981], $\mathrm{P} 1-\mathrm{C} 1=1.819(4)[1.831], \mathrm{P} 1-\mathrm{C} 9=1.825(4)[1.860], \mathrm{As} 1 \cdots \mathrm{O} 1=2.837(0)$ [3.166], P1 $\cdots \mathrm{O} 1=2.870(0)[2.990], \mathrm{P} 1-\mathrm{As} 1-\mathrm{C} 31=94.33(14)[96.8], \mathrm{P} 1-\mathrm{As} 1-\mathrm{C} 32=98.61(13)[98.1], \mathrm{C} 31-\mathrm{As} 1-\mathrm{C} 32=100.4(2)$ [100.9], As1-P1-C1 = 113.24(14) [113.4], As1-P1-C9 = 110.30(15) [108.6], $\mathrm{C} 1-\mathrm{P} 1-\mathrm{C} 9=110.4(2)[112.1], \mathrm{As} 1-\mathrm{P} 1-\mathrm{C} 30=$ 109.02(14) [110.5], C1-P1-C30 = 110.6(2) [109.8], C9-P1-C30 = 102.84(19) [101.9].

arsenium ion in the more stable phosphine-arsenium complex (reactant control). ${ }^{23}$

Chiral Auxiliary and Arsenium Complexes. The 2-(methoxymethyl)phenyl-substituted dihydrophosphepine $\left(\mathrm{a} R_{\mathrm{P}}\right)-\mathbf{1}$ was prepared by a route similar to the one used for the known phenyl-substituted compound, ${ }^{24}$ although the (aR)-2,2-dimethyl1,1-binaphthalene employed was synthesized from commercially available $(\mathrm{a} R)-1,1^{\prime}$-binaphthol. ${ }^{25}$ Condensation of dilithiated (aR)-2,2'-dimethyl-1,1'-binaphthyl, which had been isolated as the crystalline $N, N, N^{\prime}, N^{\prime}$-tetramethylethylene-1,2-diamine (TMEDA) complex, ${ }^{26}$ with dichloro[2-(methoxymethyl)phenyl]phosphine afforded the enantiomerically pure $(\mathrm{a} R)$-phosphepine, $\left(\mathrm{a} R_{\mathrm{P}}\right)-\mathbf{1}$, as air-stable, colorless needles after recrystallization from dichloromethane- $n$-hexane, mp $254{ }^{\circ} \mathrm{C}(\mathrm{dec}),[\alpha]_{\mathrm{D}}^{21}$ +210.4 ( c 1.0, $\left.\mathrm{CH}_{2} \mathrm{Cl}_{2}\right), \delta_{\mathrm{P}}-9.4\left(\mathrm{CDCl}_{3}\right)$.

The phosphine-arsenium complex $\left(\mathrm{a} R_{\mathrm{P}}\right)-\left[\mathbf{1} \rightarrow \mathrm{AsMePh} \mathrm{PF}_{6}\right.$ was prepared by the two-phase method ${ }^{19 a}$ whereby a solution of $\left(\mathrm{a} R_{\mathrm{P}}\right)-\mathbf{1}$ and iodomethylphenylarsine in dichloromethane was exposed to an excess of ammonium hexafluorophosphate in water; the air-stable complex was isolated from the organic layer as a colorless solid and was recrystallized from dichloromethanediethyl ether. The pure complex was isolated as colorless prisms of the mixed hemisolvate $\left(\mathrm{a} R_{\mathrm{P}}\right)-\left[\mathbf{1} \rightarrow \mathrm{AsMePh}_{\mathrm{PF}} \cdot 0.5 \mathrm{CH}_{2} \mathrm{Cl}_{2} \cdot\right.$ $0.5 \mathrm{Et}_{2} \mathrm{O}$, having mp $155-159^{\circ} \mathrm{C},[\alpha]_{\mathrm{D}}^{25}-53.1\left(c 1.0, \mathrm{CH}_{2} \mathrm{Cl}_{2}\right)$.

Crystal Structure. The crystal structure was determined of

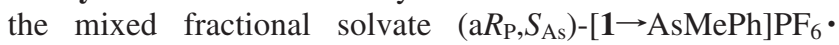
$0.26 \mathrm{CH}_{2} \mathrm{Cl}_{2} \cdot 0.37 \mathrm{Et}_{2} \mathrm{O}$, which crystallized as colorless needles from dichloromethane-diethyl ether in the hexagonal space group $P 6_{1} 22$. The solvent molecules in the lattice were disordered. The absolute configuration at arsenic in the complex is $S$, on the basis of knowledge of the absolute configuration of $\left(\mathrm{a} R_{\mathrm{P}}-1\right)$ derived from $(\mathrm{a} R)-1,1^{\prime}$-binaphthol and refinement of the

(22) Senkler, G. H.; Mislow, K. J. Am. Chem. Soc. 1972, 94, 291.

(23) Asymmetric Catalysis; Bosnich, B., Ed.;NATO ASI Series; Martinus Nijhoff Publishers: Dordrecht, 1984.

(24) (a) Gladiali, S.; Dore, A.; Fabbri, D.; De Lucchi, O.; Manassero, M. Tetrahedron: Asymmetry 1994, 5, 511-514. (b) Junge, K.; Hagemann, B.; Enthaler, S.; Spannenberg, A.; Michalik, M.; Oehme, G.; Monsees, A.; Riermeir, T.; Beller, M. Tetrahedron: Asymmetry 2004, 15, 2621-2631.

(25) Xiao, D.; Zhang, Z.; Zhang, X. Org. Lett. 1999, 1, 1679-1681.

(26) Engelhart, L. M.; Leung, W. P.; Raston, C. L.; Salem, G.; Twiss, P.; White, A. H. J. Chem. Soc., Dalton Trans. 1988, 2403-2409.
Flack parameter (Figure 1). The $\mathrm{P}-\mathrm{As}$ distance in the complex is $2.3579(12) \AA$, which is longer than the sum of the covalent radii for the two elements, viz. $2.22 \AA{ }^{27}$ and compares closely with the value of 2.3703(5) $\AA$ measured for the corresponding bond in $( \pm)-\left[\mathrm{Ph}_{2}\left(2-\mathrm{MeOCH}_{2} \mathrm{C}_{6} \mathrm{H}_{4}\right) \mathrm{P} \rightarrow \mathrm{AsMePh}_{\mathrm{PF}}\right.$; it is noteworthy that the $\mathrm{P}-\mathrm{As}$ distance in the latter is longer than the corresponding distance in $( \pm)-\left[\mathrm{Ph}_{3} \mathrm{P} \longrightarrow \mathrm{AsMePh}_{\mathrm{P}} \mathrm{PF}_{6}\right.$, viz. 2.3480(5) $\AA .{ }^{19}$ The arsenium group in the phosphepine complex is nearly planar, with a $\mathrm{C}-\mathrm{As}-\mathrm{C}$ angle of $100.4(2)^{\circ}$; the angle between the As-Me bond and the plane of the phenyl group is $5.4^{\circ}$. The $\mathrm{P}-\mathrm{As}$ bond is almost orthogonal to the plane of the arsenium ion, with $\mathrm{P} 1-\mathrm{As} 1-\mathrm{C} 31=94.33(14)^{\circ}$ and $\mathrm{P} 1-\mathrm{As} 1-$ $\mathrm{C} 32=98.61(13)^{\circ}$. The dihedral angle $\mathrm{C} 21-\mathrm{C} 20-\mathrm{C} 19-\mathrm{C} 18$ of $66.31(6)^{\circ}$ is typical of those in related phosphepines. ${ }^{24,28}$ The oxygen atom of the methoxymethyl group in the complex interacts with the arsenic at a distance of $2.837 \AA$ (sum of van der Waals radii: $3.37 \AA^{27}$ ) and the phosphorus at a distance of 2.878(1) $\AA$ (sum of van der Waals radii: $3.32 \AA^{27}$ ) and approaches from the rear with respect to the groups on arsenic, thus minimizing steric interactions between the phosphepine and the methyl and phenyl groups on the arsenium ion. [In the model compound $( \pm)-\left[\mathrm{Ph}_{2}\left(2-\mathrm{MeOCH}_{2} \mathrm{C}_{6} \mathrm{H}_{4}\right) \mathrm{P} \rightarrow \mathrm{AsMePh}_{\mathrm{PF}}\right.$, the As $\cdots \mathrm{O}$ distance is $2.878(1) \AA$ and the $\mathrm{P} \cdot . \mathrm{O}$ distance is 2.870 $\AA .{ }^{19}$ ] A number of close contacts $(<2.6 \AA)$ between the cation and the anion in the arsenium complex indicate hydrogenbonding interactions of the type $\mathrm{C}-\mathrm{H} \cdots \mathrm{F}-\mathrm{P}{ }^{29}$

NMR Spectra. The structure of the cation in $\left(\mathrm{a} R_{\mathrm{P}}, S_{\mathrm{As}}\right)$ $\left[1 \rightarrow \mathrm{AsMePh} \mathrm{PF}_{6} \cdot 0.5 \mathrm{CH}_{2} \mathrm{Cl}_{2} \cdot 0.5 \mathrm{Et}_{2} \mathrm{O}\right.$ in dichloromethane- $d_{2}$ was determined by variable-temperature NMR spectroscopy. At $25^{\circ} \mathrm{C}, \mathrm{P}-\mathrm{As}$ dissociation in the complex is fast on the NMR time scale. No ${ }^{31} \mathrm{P}$ coupling was evident for the AsMe signal, but as the temperature was lowered, $\mathrm{P}-$ As dissociation slowed and the AsMe signal resolved into a doublet. The coalescence temperature for this process is $T_{\mathrm{C}}=228 \mathrm{~K}$. At the lowest

(27) Bondi, A. J. Phys. Chem. 1964, 68, 441-451.

(28) (a) Bitterer, F.; Herd, O.; Kuhnel, M.; Stelzer, O.; Weferling, N.; Sheldrick, W.; Hahn, J.; Nagel, S.; Rosch, N. Inorg. Chem. 1998, 37, 64086417. (b) Tang, W.; Wang, W.; Chi, Y.; Zhang, Z. Angew. Chem., Int. Ed. 2003, 42, 3509.

(29) Grepioni, F.; Cojazzi, G.; Draper, S. M.; Scully, N.; Braga, D. Organometallics 1998, 17, 296-307. 


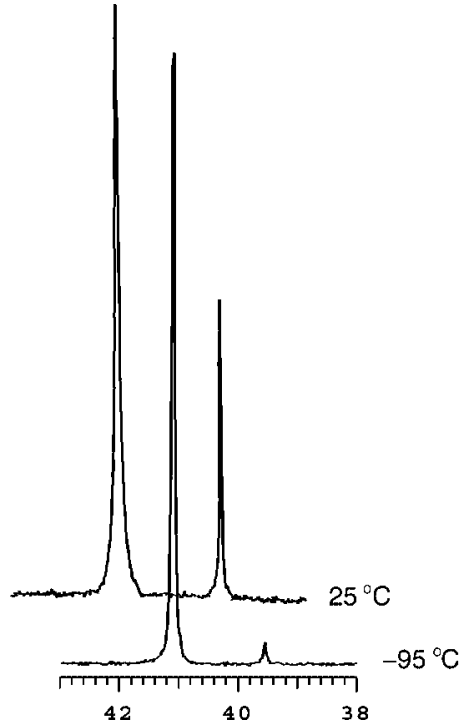

Figure 2. ${ }^{31} \mathrm{P}\left\{{ }^{1} \mathrm{H}\right\}$ NMR spectra $(204.4 \mathrm{MHz})$ of $\left(\mathrm{a} R_{\mathrm{P}}, R_{\mathrm{As}}\right) /$ $\left(\mathrm{a} R_{\mathrm{P}}, S_{\mathrm{As}}\right)-\left[1 \rightarrow \mathrm{AsMePh}_{\mathrm{PF}}\right.$ in dichloromethane- $d_{2}$.

temperature investigated $\left(-95^{\circ} \mathrm{C}\right),{ }^{3} J_{\mathrm{PH}}=16.8 \mathrm{~Hz}$. It is not straightforward to derive a rate constant for $\mathrm{P}-\mathrm{As}$ dissociation from these data, because of the two $\mathrm{P}-\mathrm{As}$ bonds in question that of the $\mathrm{a} R_{\mathrm{P}}, R_{\mathrm{As}}$ diastereomer and that of the $\mathrm{a} R_{\mathrm{P}}, S_{\mathrm{As}}$ diastereomer - and because the resonances for the minor diastereomer are obscured by those of the major diastereomer. It is nevertheless noteworthy that the coalescence temperature for the AsMe resonances for $\left(\mathrm{a} R_{\mathrm{P}}, R_{\mathrm{As}}\right) /\left(\mathrm{a} R_{\mathrm{P}}, S_{\mathrm{As}}\right)-[\mathbf{1} \rightarrow \mathrm{AsMePh}] \mathrm{PF}_{6}$ is lower than those reported for the corresponding resonances for the adducts $( \pm)-\left[\mathrm{Me}_{2} \mathrm{PhP} \rightarrow \mathrm{AsMePh}_{\mathrm{PF}}\left(T_{\mathrm{C}}\right.\right.$ ca. $\left.313 \mathrm{~K}\right),( \pm)-\left[\mathrm{Ph}_{3} \mathrm{P} \rightarrow\right.$ AsMe$\mathrm{Ph}] \mathrm{PF}_{6}\left(T_{\mathrm{C}} 281 \mathrm{~K}\right)$, and even $( \pm)-\left[\mathrm{Ph}_{2}\left(2-\mathrm{MeOCH}_{2} \mathrm{C}_{6} \mathrm{H}_{4}\right)-\right.$ $\mathrm{P} \rightarrow \mathrm{AsMePh}_{\mathrm{P}} \mathrm{PF}_{6}\left(T_{\mathrm{C}} 273 \mathrm{~K}\right) .{ }^{19}$ Clearly, the combined effects of the $\mathrm{P} \cdots \mathrm{O}$ and $\mathrm{As} \cdots \mathrm{O}$ interactions involving the 2-(methoxymethyl)phenyl group in the phosphepine complex emphatically counteract the enhancement of donor ability arising from the two methylene groups within the phosphepine ring.

At $-95^{\circ} \mathrm{C}, \mathrm{P}-\mathrm{As}$ dissociation in $\left(\mathrm{a} R_{\mathrm{P}}, R_{\mathrm{As}}\right) /\left(\mathrm{a} R_{\mathrm{P}}, S_{\mathrm{As}}\right)-[1 \rightarrow \mathrm{As}-$ $\mathrm{MePh}] \mathrm{PF}_{6}$ is slow on the NMR time scale. Integration of the ${ }^{31} \mathrm{P}\left\{{ }^{1} \mathrm{H}\right\}$ NMR spectrum of the complex in dichloromethane- $d_{2}$ at $-95{ }^{\circ} \mathrm{C}$ indicated a $97: 3$ mixture of the two diastereomers (94\% de) (Figure 2). The standard free energy difference between the two diastereomers (averaged over all conformations) at this temperature is $\Delta G^{\circ}=5.1 \mathrm{~kJ} \mathrm{~mol}^{-1} .30$

Use of two-dimensional techniques allowed a complete assignment of the ${ }^{1} \mathrm{H}$ NMR spectrum of the complex, with the exception of the resonances for the AsPh protons, which were too broad for accurate assignment. The assignments for the stereochemical picture of the adduct in solution were derived from the NOEs, as shown in Figure 3. If it is assumed that the rate of molecular tumbling in solution is the same for both diastereomers and hence their relaxation properties are equivalent, then since the major diastereomer is present in large excess, the nuclear Overhauser enhancements (NOEs) that can be detected at low temperature will provide a snapshot of the major diastereomer alone. ${ }^{30}$

Thus, at low temperature $\left(-78{ }^{\circ} \mathrm{C}\right)$, NOE correlations involving the $\mathrm{PCH}_{2}$ and $P$-aryl protons indicated that the $-\mathrm{CH}_{2} \mathrm{OCH}_{3}$ group was preferentially oriented toward the rear of the molecule in the projection shown in the figure. NOE

(30) Sanders, J. K. M.; Hunter, B. K. Modern NMR Spectroscopy, 2nd ed.; Oxford University Press: Oxford, 1993; Chapter 6. (a)

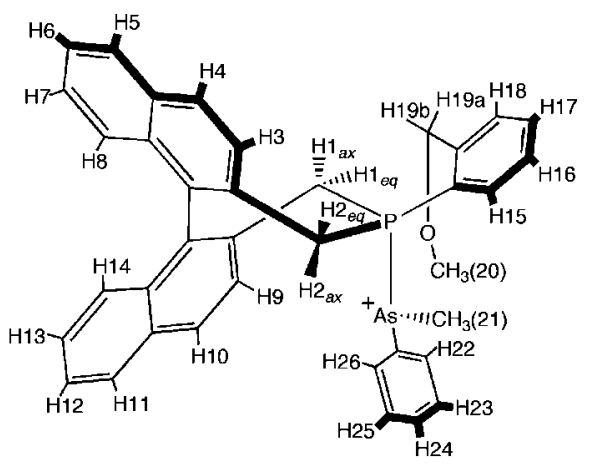

(b)

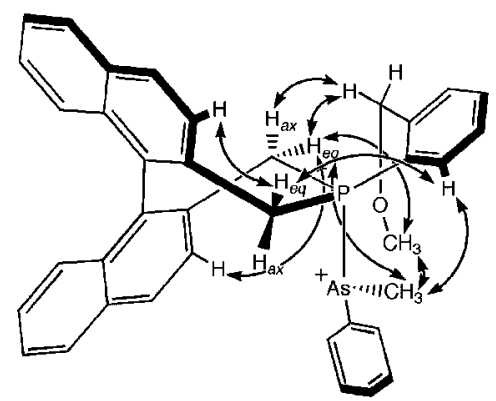

Figure 3. Atom-labeling scheme for ${ }^{1} \mathrm{H}$ NMR spectroscopic assignments (a) and NOEs for the $\mathrm{a} R_{\mathrm{P}}, S_{\mathrm{As}}$ (major) diastereomer of the cation of $\left(\mathrm{a} R_{\mathrm{P}}, S_{\mathrm{As}}\right)-\left[\mathbf{1} \rightarrow \mathrm{AsMePh}_{\mathrm{PF}}\right.$ in dichloromethane- $d_{2}(\mathrm{~b})$.

correlations involving the AsMe, OMe, and one of the $\mathrm{PCH}_{2}$ protons (only detected at room temperature) indicate that (a) the AsMe group lies toward the rear in Figure 3 and (b) the OMe group is in close proximity $(<4 \AA)$ to the AsMe group (as required for an As $\cdots$ O interaction). This latter point should be disfavored purely on entropic and steric grounds and gives credence to the notion that the As $\cdots \mathrm{O}$ and $\mathrm{P} \cdots \mathrm{O}$ interactions operate in solution as stabilizing mechanisms.

Variable-temperature ${ }^{1} \mathrm{H}$ NMR spectra over the range -95 to $25^{\circ} \mathrm{C}$ indicated that the phosphepine- $\mathrm{PCH}_{2}$ signals broadened and shifted as the temperature was lowered, which is consistent with a dynamic rotational equilibrium about the $\mathrm{P}-\mathrm{As}$ bond. The most stable conformation places the $\mathrm{PCH}_{2}$ protons closer to the shielding region of the AsPh group than is the case, on average, at room temperature (Figure 4). The signals for $\mathrm{H} 1_{e q}$ and $\mathrm{H} 1_{a x}$ broaden slightly as the temperature is lowered (as do most of the other signals). By contrast, the $\mathrm{H} 2{ }_{a x}$ signal sharpens to the extent that ${ }^{2} J_{\mathrm{HH}}$ and ${ }^{2} J_{\mathrm{PH}}$ coupling are evident at $-70{ }^{\circ} \mathrm{C}$ and below. This is because the reduction in the number of accessible $\mathrm{P}-\mathrm{As}$ conformations at low temperatures makes the location of the $\mathrm{H} 2_{a x}$ with respect to the AsPh shielding region less variable. When rotation about the $\mathrm{P}-\mathrm{As}$ bond is modeled with the AsMePh group having the configuration of the less stable diastereomer $\left(\mathrm{a} R_{\mathrm{P}}, R_{\mathrm{As}}\right)$, serious structural barriers are present that are absent for the $\left(\mathrm{a} R_{\mathrm{P}}, S_{\mathrm{As}}\right)$ diastereomer, which supports the notion that the more stable diastereomer of the complex in dichloromethane has the relative configuration $\left(\mathrm{a} R_{\mathrm{P}}, S_{\mathrm{As}}\right)$.

Enantiomeric Purity and Absolute Configuration. (a) Reference Compounds. The enantioselectivity of the asymmetric synthesis and the absolute configuration of the arsine produced were determined by reaction of the arsine with the enantiomerically pure, chloro-bridged dipalladium complex $\left(S_{\mathrm{C}}, S_{\mathrm{C}}\right)-\mathbf{3} \cdot \mathrm{CH}_{2} \mathrm{Cl}_{2}$ in chloroform- $d$ and recording the ${ }^{1} \mathrm{H}$ NMR spectrum of the resulting mixture of monopalladium complexes 

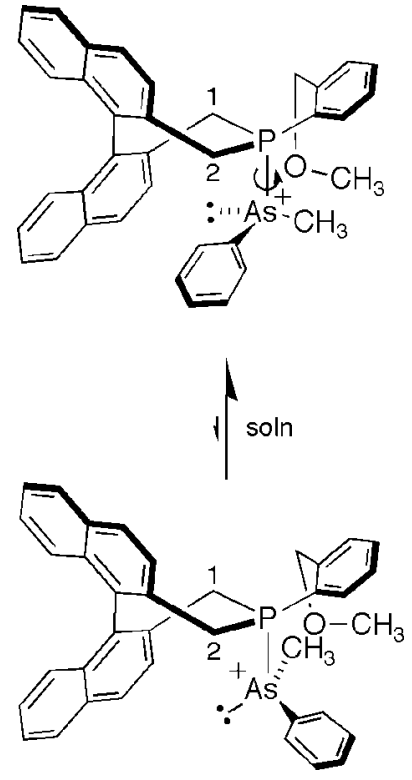

Figure 4. Conformational equilibrium about the $\mathrm{P}-\mathrm{As}$ bond in $\left(\mathrm{a} R_{\mathrm{P}}, S_{\mathrm{As}}\right)-\left[\mathbf{1} \rightarrow \mathrm{AsMePh}_{\mathrm{P}} \mathrm{PF}_{6}\right.$ in dichloromethane- $d_{2}$.

Scheme 2

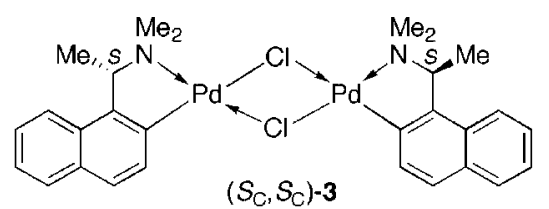

$$
\mid \begin{gathered}
2( \pm)-2 \\
\left(\mathrm{CH}_{2} \mathrm{Cl}_{2}\right)
\end{gathered}
$$

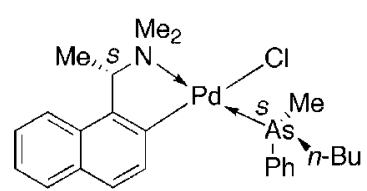

$\left(S_{C}, S_{A S}\right)-4$

$X$-ray

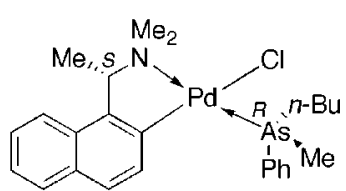

$\left(S_{C}, R_{A s}\right)-4$
$\left(S_{\mathrm{C}}, R_{\mathrm{As}}\right)-\mathbf{4}$ and $\left(S_{\mathrm{C}}, S_{\mathrm{As}}\right)-\mathbf{4}$ (Scheme 2$) .{ }^{31}$ The identities of the two diastereomers of the monopalladium complex were determined by carrying out a resolution of $( \pm)-2$ with $\left(S_{\mathrm{C}}, S_{\mathrm{C}}\right)$ $3 \cdot \mathrm{CH}_{2} \mathrm{Cl}_{2}$ and characterizing the least soluble diastereomer by NMR spectroscopy and X-ray crystallography. Thus, 1 equiv of $( \pm)-2$ was added to a solution containing half an equivalent of $\left(S_{\mathrm{C}}, S_{\mathrm{C}}\right)-\mathbf{3} \cdot \mathrm{CH}_{2} \mathrm{Cl}_{2}$ in dichloromethane, whereupon the deep yellow color of the dimer faded to the pale yellow color of the bridge-split monomer $\left(S_{\mathrm{C}}, R_{\mathrm{As}}\right) /\left(S_{\mathrm{C}}, S_{\mathrm{As}}\right)-4$. The bridge-splitting of the dimer by arsines (and phosphines) is highly regioselective in favor of the product in which the arsine is trans to the dimethylamino group in the orthometalated ring. ${ }^{14}$ The ${ }^{1} \mathrm{H}$ NMR spectrum of a sample taken from the reaction mixture within ca. 5 min indicated complete conversion of the dimer into the mononuclear product, viz. a 1:1 pair of baseline-separated $\mathrm{AsCH}_{2} \mathrm{CH}_{2} \mathrm{CH}_{2} \mathrm{CH}_{3}$ triplets centered at $\delta 0.74$ and 0.91 for the two trans diastereomers $\left(S_{\mathrm{C}}, R_{\mathrm{As}}\right) /\left(S_{\mathrm{C}}, S_{\mathrm{As}}\right)-\mathbf{4}$, as shown in Figure 5a. The solvent was evaporated from the reaction mixture, and

(31) (a) Roberts, N. K.; Wild, S. B. J. Chem. Soc., Dalton Trans. 1979, 2015-2021. (b) Hockless, D. C. R.; Gugger, P. A.; Leung, P. H.; Mayadunne, R. C.; Pabel, M.; Wild, S. B. Tetrahedron 1997, 53, 40834094. the residue was recrystallized from acetone (wet); after three recrystallizations, the less soluble fraction exhibited, in its ${ }^{1} \mathrm{H}$ NMR spectrum in chloroform- $d$, only the $\mathrm{AsCH}_{2} \mathrm{CH}_{2} \mathrm{CH}_{2} \mathrm{CH}_{3}$ signal at $\delta 0.74$. The identity of the diastereomer responsible for this peak was determined by a single-crystal X-ray structure analysis on the isolated compound; the structure of $\left(S_{\mathrm{C}}, R_{\mathrm{As}}\right)-\mathbf{4}$ is shown in Figure 6. [Note that coordination of an $A s$-chiral arsine to a metal is stereospecific: the apparent inversion of configuration that takes place at arsenic when a free arsine coordinates to an element of higher atomic number than 12 is a consequence of the Cahn-Ingold-Prelog (CIP) rules. ${ }^{20}$ Upon coordination to the palladium, the lone pair on the free arsine of CIP priority 4 is replaced by a ligand (the metal) of CIP priority 1.] Thus, the $\mathrm{AsCH}_{2} \mathrm{CH}_{2} \mathrm{CH}_{2} \mathrm{CH}_{3}$ triplets centered at $\delta$ 0.74 and 0.91 in chloroform- $d$ correspond to the diastereomers $\left(S_{\mathrm{C}}, R_{\mathrm{As}}\right)-\mathbf{4}$ and $\left(S_{\mathrm{C}}, S_{\mathrm{As}}\right) \mathbf{- 4}$, respectively, and are convenient signals for the determination by ${ }^{1} \mathrm{H}$ NMR spectroscopy of the amounts of $\left(R_{\mathrm{As}}\right)$ - and $\left(S_{\mathrm{As}}\right)-2$ that were originally present.

(b) Asymmetric Synthesis. A solution of $n$-butyllithium (1.1 equiv, 1.4 $\mathrm{M}$ in hexanes) was added to a solution of $\left(\mathrm{a} R_{\mathrm{P}}, R_{\mathrm{As}}\right) /$ $\left(\mathrm{a} R_{\mathrm{P}}, S_{\mathrm{As}}\right)-\left[1 \rightarrow \mathrm{AsMePh}_{\mathrm{P}} \mathrm{PF}_{6} \cdot 0.5 \mathrm{CH}_{2} \mathrm{Cl}_{2} \cdot 0.5 \mathrm{Et}_{2} \mathrm{O}\right.$ ( 1 equiv) in dichloromethane at $-95{ }^{\circ} \mathrm{C}$. [ $n$-Butyllithium does not react appreciably with dichloromethane at temperatures below -74 ${ }^{\circ} \mathrm{C} .{ }^{32}$ ] The reaction mixture was stirred for ca. $5 \mathrm{~min}$, and then water was added and the cooling bath removed. When the mixture had reached room temperature, the solvents were removed from the product by evaporation. The residues were redissolved in dichloromethane, and a suspension containing an excess of $\left(S_{\mathrm{C}}, S_{\mathrm{C}}\right)-\mathbf{3} \cdot \mathrm{CH}_{2} \mathrm{Cl}_{2}$ in dichloromethane was added. After ca. $15 \mathrm{~min}$, the yellow solution was concentrated to a small volume and transferred to a short silica/dichloromethane column. The first fraction (excess $\left.\left(S_{\mathrm{C}}, S_{\mathrm{C}}\right)-3\right)$ was eluted from the column with neat dichloromethane; the second fraction (mixture of $\left(S_{\mathrm{C}}, R_{\mathrm{As}}\right) /\left(S_{\mathrm{C}}, S_{\mathrm{As}}\right)-\mathbf{4}$ and the corresponding palladium complex containing $\left.\left(\mathrm{a} R_{P}\right)-\mathbf{1}\right)$ was eluted with $10 \%$ diethyl ether-dichloromethane. This purification method was shown not to enrich either diastereomer of a 1:1 mixture of $\left(S_{\mathrm{C}}, R_{\mathrm{As}}\right) /$ $\left(S_{\mathrm{C}}, S_{\mathrm{As}}\right)-4$ (Figure 5a). Integration of the AsMe singlets and $\mathrm{AsCH}_{2} \mathrm{CH}_{2} \mathrm{CH}_{2} \mathrm{CH}_{3}$ triplets in the ${ }^{1} \mathrm{H}$ NMR spectrum of the second fraction gave $\left.\left(S_{\mathrm{C}}, R_{\mathrm{As}}\right) / S_{\mathrm{C}}, S_{\mathrm{As}}\right)-4=85: 15$ (Figure $5 \mathrm{~b}$ ), which corresponds to an enantioselectivity of the arsine of $85 \%$ in favor of the $S$ isomer ( $70 \%$ enantiomeric excess). Since the position of equilibrium depends upon the relative stabilities of the two diastereomers under the reaction conditions and the carbanionic reagent adds irreversibly to the arsenium centers of the equilibrating mixture of diastereomers at a rate that is faster than the rate of phosphine exchange between the diastereomers, the enantiomeric excess of the arsine should correspond to the diastereomeric excess at that temperature. The discrepancy between the observed ee of the arsine $(70 \%)$ and the de of the substrate $(94 \%)$ can be attributed to the attack of the $n$ butyllithium on the dissociated, prochiral methylphenylarsenium ion, which will be nonenantioselective and more rapid than attack on the less electropositive phosphine-stabilized species. In this context, it is noteworthy that phosphine exchange in $\left(\mathrm{a} R_{\mathrm{P}}, R_{\mathrm{As}}\right) /\left(\mathrm{a} R_{\mathrm{P}}, S_{\mathrm{As}}\right)-[\mathbf{1} \rightarrow \mathrm{AsMePh}] \mathrm{PF}_{6}$ in dichloromethane- $d_{2}$, as indicated by the coalescence temperature of $228 \mathrm{~K}$ for the AsMe resonances of the two diastereomers, is much faster than for closely related model complexes in the same solvent (see above).

The reaction of the phosphepine-arsenium complex with $n$-butyllithium does not proceed in $n$-hexane or diethyl ether, in which the configurationally pure complex is insoluble, even

(32) Köbrich, G.; Merkle, H. R. Chem. Ber. 1966, 99, 1782-1792. 


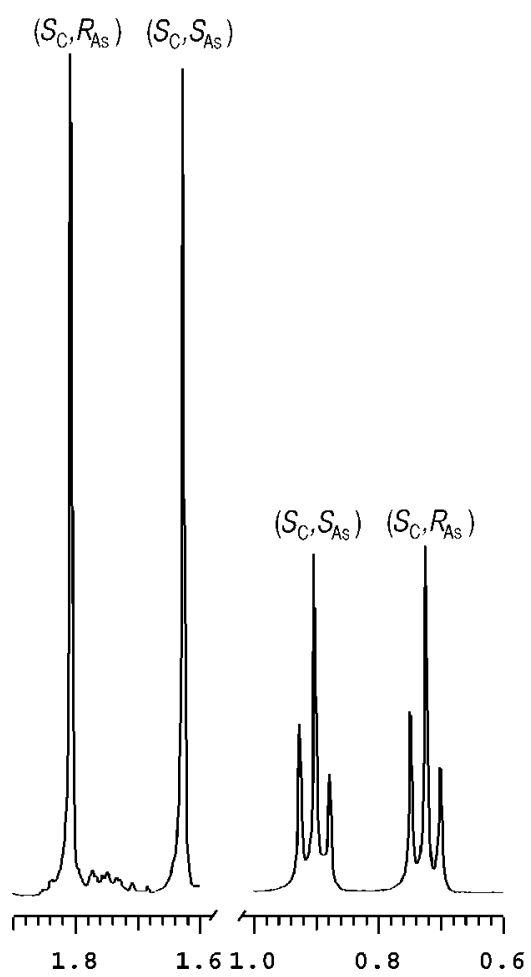

(a)

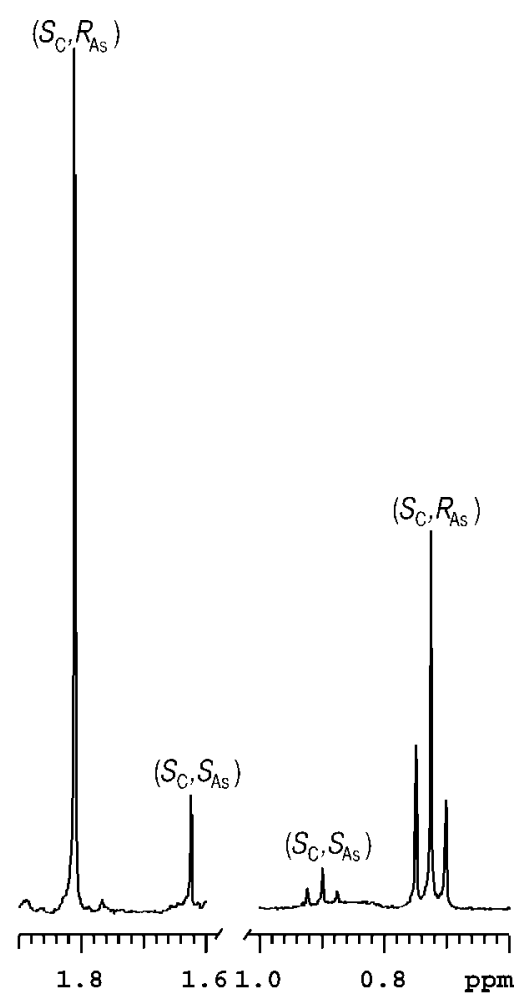

(b)

Figure 5. ${ }^{1} \mathrm{H} \mathrm{NMR}\left(300 \mathrm{MHz}, 25^{\circ} \mathrm{C}\right)$ spectra in $\mathrm{AsCH}$ (singlet) and $\mathrm{AsCH}_{2} \mathrm{CH}_{2} \mathrm{CH}_{2} \mathrm{CH}_{3}$ (triplet) regions of $\left(S_{\mathrm{C}}, R_{\mathrm{As}}\right) /\left(S_{\mathrm{C}}, S_{\mathrm{As}}\right)-4$ in chloroform$d$ : (a) $\left(S_{\mathrm{C}}, R_{\mathrm{As}}\right) /\left(S_{\mathrm{C}}, S_{\mathrm{As}}\right)=1: 1$ mixture from reaction of $( \pm)-\mathbf{2}$ with $\left(S_{\mathrm{C}}, S_{\mathrm{C}}\right)-\mathbf{3} \cdot \mathrm{CH}_{2} \mathrm{Cl}_{2}$; and (b) $\left(S_{\mathrm{C}}, R_{\mathrm{As}}\right) /\left(S_{\mathrm{C}}, S_{\mathrm{As}}\right)=85: 15$ mixture from reaction of enantiomerically enriched $(S)-\mathbf{2}$ obtained from asymmetric synthesis with $\left(S_{\mathrm{C}}, S_{\mathrm{C}}\right)-\mathbf{3} \cdot \mathrm{CH}_{2} \mathrm{Cl}_{2}$.

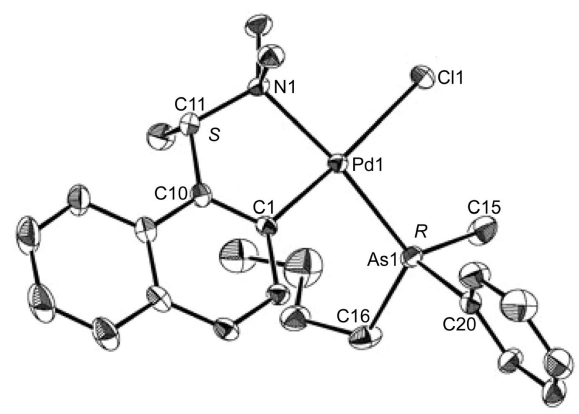

Figure 6. Molecular structure and absolute configuration of $\left(S_{\mathrm{C}}, R_{\mathrm{As}}\right)-\mathbf{4}$ showing $30 \%$ probability ellipsoids. Selected bond distances $(\AA)$ and interbond angles $(\mathrm{deg})$ : Pd1-As1 $=2.3558(4)$, $\mathrm{Pd} 1-\mathrm{Cl} 1=2.3939(8), \mathrm{Pd} 1-\mathrm{N} 1=2.122(2), \mathrm{Pd} 1-\mathrm{C} 1=1.997(3)$, $\mathrm{As} 1-\mathrm{C} 15=1.942(3), \mathrm{As} 1-\mathrm{C} 16=1.958(4), \mathrm{As} 1-\mathrm{C} 20=1.942(3)$, $\mathrm{As} 1-\mathrm{Pd} 1-\mathrm{N} 1=170.65(7), \mathrm{C} 1-\mathrm{Pd} 1-\mathrm{Cl} 1=170.30(8), \mathrm{Pd} 1-\mathrm{As} 1-\mathrm{C} 15$ $=114.4(1), \mathrm{Pd} 1-\mathrm{As} 1-\mathrm{C} 16=116.1(1), \mathrm{Pd} 1-\mathrm{As} 1-\mathrm{C} 20=118.9(1)$, $\mathrm{Pd} 1-\mathrm{C} 1-\mathrm{C} 10=114.2(2), \mathrm{Pd} 1-\mathrm{N} 1-\mathrm{C} 11=106.6(2)$.

at room temperature. When THF was used as the solvent, a reaction between the arsenium complex in solution and $n$ butyllithium at $-78{ }^{\circ} \mathrm{C}$ led to racemic arsine. This is consistent with the ratio $\left(\mathrm{a} R_{\mathrm{P}}, R_{\mathrm{As}}\right) /\left(\mathrm{a} R_{\mathrm{P}}, S_{\mathrm{As}}\right)-\left[1 \rightarrow \mathrm{AsMePh} \mathrm{PF}_{6}\right.$ ca. $1: 1$ observed by NMR spectroscopy for the complex in tetrahydrofuran- $d_{8}$ at $-78{ }^{\circ} \mathrm{C}$. The lack of diasteroselectivity in the complex in this solvent is considered to be due to a disruption of the discriminatory intramolecular As $\cdots \mathrm{O}, \mathrm{P} \cdots \mathrm{O}$ interactions.

The importance of the 2-methoxymethyl group on the phenyl substituent of the phosphepine to the success of the asymmetric synthesis of the arsine was confirmed by synthesizing the known phenyl-substituted phosphepine $\left(\mathrm{a} R_{\mathrm{P}}\right)-\mathbf{5}$ and using it as the chiral auxiliary. The ${ }^{31} \mathrm{P}\{\mathrm{H}\}$ NMR spectrum of $\left(\mathrm{a} R_{\mathrm{P}}, R_{\mathrm{As}}\right) /\left(\mathrm{a} R_{\mathrm{P}}, S_{\mathrm{As}}\right)-$ $\left[\mathbf{5} \rightarrow \mathrm{AsMePh}_{\mathrm{P}} \mathrm{PF}_{6}\right.$ in dichloromethane at $-78^{\circ} \mathrm{C}$ contained two singlets at $\delta 37.7$ (major) and $\delta 38.7$ (minor) in the intensity ratio major/minor ca. 58:42 (16\% de). This relatively low diastereoselectivity in the absence of the 2-methoxymethyl group strongly supports the case for its involvement in the diastereofacial discrimination between the phosphepine and the prochiral methylphenylarsenium ion. Most likely, the absence of the As $\cdots \mathrm{O}, \mathrm{P} \cdots \mathrm{O}$ interactions in the complex makes rotation about the $\mathrm{P}-\mathrm{As}$ bond more facile and enables the substituents on the arsenium ion to be placed further from the chiral binaphthyl framework, hence reducing the stereochemical influence of the auxiliary. Because of the significance of the 2-(methoxymethyl)phenyl group on the diastereoselectivity of coordination to the methylphenylarsenium, a detailed computational investigation of the interaction of the group with the arsenic was undertaken.

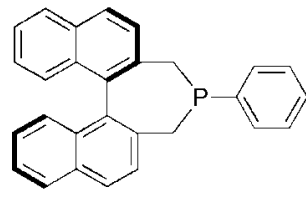

$\left(\mathrm{a} R_{\mathrm{P}}\right)-5$

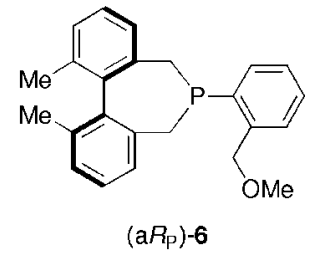

$\left(a R_{p}\right)-6$
Computational Investigation. The diastereomer ratio (dr) for $\left(\mathrm{a} R_{\mathrm{P}}, R_{\mathrm{As}}\right) /\left(\mathrm{a} R_{\mathrm{P}}, S_{\mathrm{As}}\right)-[\mathbf{1} \rightarrow \mathrm{AsMePh}] \mathrm{PF}_{6}$ is a macroscopic property that reflects the combined contributions of many conformers of each diastereomer. Thus, in order to rationalize which diastereomer of the cation predominates, a computational analysis of all significant conformers for each diastereomer was undertaken. Because of the large numbers of atoms in the molecules, density functional theory (DFT) at the B3LYP/6$311+\mathrm{G}(3 \mathrm{df}, 2 \mathrm{p})$ level was the technique of choice for the energy calculations. Even with the reduced computational demands of 
DFT, however, economy was still a concern, and so the simplified phosphepine-arsenium cation $\left(\mathrm{a} R_{\mathrm{P}}, R_{\mathrm{As}}\right) /\left(\mathrm{a} R_{\mathrm{P}}, S_{\mathrm{As}}\right)-$ $[6 \rightarrow \mathrm{AsMePh}]^{+}$was chosen as the model complex. A comparison of the optimized geometries for the 1,1'-binaphthyl- and 6,6'-dimethyl-1,1'-biphenyl-based phosphepine adducts confirmed that the dihedral angle for the biaryl component of each ligand was reproduced to within $1.5^{\circ}$ in the simpler structure.

The total energies of the conformers for the two diastereomers of the cation were spread over a range of nearly $40 \mathrm{~kJ} \mathrm{~mol}^{-1}$. Assuming all of the conformers are in equilibrium at experimental temperatures, then the amounts of each conformer present at a given temperature can be calculated by application of the Boltzmann distribution law to the molecular free energies. ${ }^{33}$ The (macroscopic) dr at that temperature can then be calculated by summation. The calculated $\mathrm{dr}$ for $\left(\mathrm{a} R_{\mathrm{P}}, R_{\mathrm{As}}\right) /$ $\left(\mathrm{a} R_{\mathrm{P}}, S_{\mathrm{As}}\right)-[6 \rightarrow \mathrm{AsMePh}]^{+}$at $-95{ }^{\circ} \mathrm{C}$ is $\left(\mathrm{a} R_{\mathrm{P}}, R_{\mathrm{As}}\right) /\left(\mathrm{a} R_{\mathrm{P}}, S_{\mathrm{As}}\right)=$ $0.05 / 99.5$ (de: $99 \%$ ). This value of the de is higher than the experimentally determined de for $\left(\mathrm{a} R_{\mathrm{P}}, R_{\mathrm{As}}\right) /\left(\mathrm{a} R_{\mathrm{P}}, S_{\mathrm{As}}\right)-[\mathbf{1} \rightarrow \mathrm{As}-$ $\mathrm{MePh}] \mathrm{PF}_{6}$ in dichloromethane- $d_{2}$ at this temperature, viz. $94 \%$, which in turn is closer to the calculated value at $25{ }^{\circ} \mathrm{C}$ for $\left(\mathrm{a} R_{\mathrm{P}}, R_{\mathrm{As}}\right) /\left(\mathrm{a} R_{\mathrm{P}}, S_{\mathrm{As}}\right)-[6 \rightarrow \mathrm{AsMePh}]^{+}(\mathrm{dr}=3.8 / 96.2 ; \mathrm{de}=92.4 \%)$. The discrepancy may reflect an error in the calculations, which, by necessity, are based on a relatively low level of theory and ignore solvent effects and employ a simpler model for the phosphepine (6 instead of 1). In support of the calculations, however, the calculated structure of the minimum energy complex is very similar to the structure found in the crystal, which implies that the key interactions in the complex have been modeled correctly (Figure 1). In particular, the almost eclipsed conformation of the substituents about the $\mathrm{P}-\mathrm{As}$ bond in the calculated structure of $\left(\mathrm{a} R_{\mathrm{P}}, S_{\mathrm{As}}\right)-[\mathbf{6} \rightarrow \mathrm{AsMePh}]^{+}$is very similar to that found in the crystal structure of $\left(\mathrm{a} R_{\mathrm{P}}, S_{\mathrm{As}}\right)$ $\left[1 \rightarrow \mathrm{AsMePh}_{\mathrm{P}} \mathrm{PF}_{6}\right.$ and appears to be a principal reason for the stereodifferentiation between the two diastereomers.

As discussed above, the experimental investigations indicate that the 2-(methoxymethyl)phenyl substituent on the phosphorus of the phosphepine is crucial for significant diastereofacial discrimination between the phosphepine and the prochiral methylphenylarsenium ion, and it was postulated that As $\cdots \mathrm{O}$ and $\mathrm{P} \cdots \mathrm{O}$ interactions hinder rotation about the $\mathrm{P}-\mathrm{As}$ bonds in the diastereomers. An examination of the experimental and calculated geometries of the lowest-energy conformer of $\left(\mathrm{a} R_{\mathrm{P}-}\right.$ ,$\left.S_{\mathrm{As}}\right)-[1 \rightarrow \mathrm{AsMePh}]^{+}$confirms that the As $\cdots \mathrm{O}$ and $\mathrm{P} \cdots \mathrm{O}$ distances are relatively short (ca. $3 \AA$ ) in both cases (Figure 1). The importance of these anchimeric interactions can be determined by comparing the electronic energies of the two lowestenergy conformers of $\left(\mathrm{a} R_{\mathrm{P}}, S_{\mathrm{As}}\right)-[6 \rightarrow \mathrm{AsMePh}]^{+}$with the corresponding structures in which the $2-\left(\mathrm{CH}_{3} \mathrm{OCH}_{2}\right)-\mathrm{C}_{6} \mathrm{H}_{4} \mathrm{P}$ bond is rotated such that the $\mathrm{As} \cdots \mathrm{O}$ and $\mathrm{P} \cdots \mathrm{O}$ interactions are no longer possible (see Figure S2 of the Supporting Information). When this comparison is made, it is found that the energies of the two conformers lacking the As $\cdots \mathrm{O}$ and $\mathrm{P} \cdots \mathrm{O}$ interactions are higher by 22.2 and $23.4 \mathrm{~kJ} \mathrm{~mol}^{-1}$. Moreover, in the optimized geometries of the higher-energy conformers, the substituents about the $\mathrm{P}-\mathrm{As}$ bonds are staggered rather than eclipsed. This observation is a further indication that the anchimeric As $\cdots \mathrm{O}$ and $\mathrm{P} \cdots \mathrm{O}$ interactions in the lowest-energy conformers restrict rotation about the $\mathrm{P}-\mathrm{As}$ bond and force the complex to adopt the otherwise unfavorable eclipsed conformation that maximizes interactions between the substituents on the arsenium ion and the chiral phosphepine.

(33) Laidler, K. J.; Meiser, J. H. Physical Chemistry, 2nd ed.; Houghton Mifflin: Boston, 1995; pp 703-706.

\section{Conclusion}

The asymmetric synthesis of a tertiary arsine chiral at arsenic has been achieved by carbanion addition to a phosphinestabilized methylphenylarsenium salt in which the phosphine is an enantiomerically pure phosphepine derived from $(\mathrm{a} R)-1,1^{\prime}$ binaphthol. When the seven-membered $\left(\mathrm{a} R_{\mathrm{P}}\right)$-phosphepine carried a 2-(methoxymethyl)phenyl substituent at phosphorus and the reaction was carried out at $-95^{\circ} \mathrm{C}$ in dichloromethane, an enantioselectivity of $85 \%$ (70\% enantiomeric excess) was obtained for the synthesis of $(S)$-(n-butyl)methylphenylarsine from the corresponding phosphine-stabilized arsenium hexafluorophosphate by the addition of $n$-butyllithium. The significance of the chelating 2-(methoxymethyl)phenyl group on phosphorus on the diastereoselectivity of coordination of the phosphepine to the prochiral methylphenylarsenium ion was verified by detailed NMR spectroscopic investigations, an X-ray crystal structure analysis, and DFT calculations.

\section{Experimental Section}

General Comments. Operations involving air-sensitive compounds were performed under nitrogen with use of Schlenk techniques. Solvents were dried over appropriate drying agents and distilled before use. ${ }^{34}$ Reaction temperatures of -78 and $-95{ }^{\circ} \mathrm{C}$ refer, respectively, to acetone-dry ice and ethanol-liquid nitrogen slush baths. NMR spectra were recorded on Varian Gemini 300, Mercury 300, and Inova 300, 500, and 600 spectrometers. For ${ }^{31} \mathrm{P}$ spectra, chemical shifts are quoted relative to external $85 \%$ aqueous $\mathrm{H}_{3} \mathrm{PO}_{4}$, with positive shifts lying downfield of the standard. Unless otherwise stated, NMR spectra were recorded at $25{ }^{\circ} \mathrm{C}$. EI mass spectra were recorded on a VG Autospec M series sector instrument, and ESI mass spectra were recorded on a VG Quattro II triple quadruple spectrometer. Optical rotations were measured on the specified solutions with a Perkin-Elmer model 241 spectropolarimeter. Specific rotations are within $\pm 0.05 \mathrm{deg} \mathrm{cm}^{2} \mathrm{~g}^{-1}$. Elemental analyses were performed by staff within the Research School of Chemistry. Dichloro[2-(methoxymethyl)phenyl]phosphine, ${ }^{35}(\mathrm{a} R)$ $\left[\{\operatorname{Li}(T M E D A)\}_{2}\left\{2,2^{\prime}\right.\right.$-dimethylyl-1,1'-binaphthyl $\left.\}\right],{ }^{26}$ iodomethylphenylarsine, ${ }^{36}\left(\mathrm{a} R_{\mathrm{P}}\right)-\mathbf{5},{ }^{24}$ chloromethylphenylarsine, ${ }^{37}$ and $\left(S_{\mathrm{C}}, S_{\mathrm{C}}\right)-$ $3 \cdot \mathrm{CH}_{2} \mathrm{Cl}_{2}{ }^{31 \mathrm{~b}}$ were prepared by the literature methods.

$\left(\mathrm{a} \boldsymbol{R}_{\mathrm{P}}\right)-4$-[(2-Methoxymethyl)phenyl])-4,5-dihydro-3H-dinaphtho $\left[2,1-c ; 1^{\prime}, 2^{\prime}-e\right]$ phosphepine, $\left(\mathbf{a} R_{\mathbf{P}}\right)-1$. A solution of dichloro[(2methoxymethyl)phenyl]phosphine $(2.32 \mathrm{~g}, 10.4 \mathrm{mmol})$ in $n$-hexane $(25 \mathrm{~mL})$ was added dropwise over $1.5 \mathrm{~h}$ to a suspension of $(\mathrm{a} R)$ $\left[\{\operatorname{Li}(\text { TMEDA })\}_{2}\left\{2,2^{\prime}\right.\right.$-dimethylyl-1,1'-binaphthyl $\left.\}\right]$ (4.83 g, 9.17 mmol) in $n$-hexane $(50 \mathrm{~mL})$ at $0{ }^{\circ} \mathrm{C}$, and the mixture was heated under reflux overnight. The yellow suspension was cooled to room temperature, and toluene $(25 \mathrm{~mL})$ and water $(50 \mathrm{~mL})$ were added. The two phases were separated, and the aqueous phase was extracted with dichloromethane $(4 \times 30 \mathrm{~mL})$. The organic layers were combined, dried over $\mathrm{MgSO}_{4}$, and freed of solvent under vacuum. This gave the crude product as a yellow solid, which was redissolved in dichloromethane (ca. $50 \mathrm{~mL}$ ) and eluted through a small plug of silica with additional solvent (ca. $100 \mathrm{~mL}$ ). The solvent was removed from the eluate to afford the crude product as apale yellow solid that was recrystallized from dichloromethane-hexane to give the pure product as colorless needles: $2.4 \mathrm{~g}(60 \%)$, mp 254 ${ }^{\circ} \mathrm{C}(\mathrm{dec}) ;[\alpha]_{\mathrm{D}}^{21}+210.4\left(c 1.0, \mathrm{CH}_{2} \mathrm{Cl}_{2}\right)$. Anal. Calcd for $\mathrm{C}_{30} \mathrm{H}_{25} \mathrm{OP}$ : C, 83.3, H, 5.8, P, 7.2. Found: C, 82.5, H, 5.9, P, 6.9. ${ }^{1} \mathrm{H}$ NMR

(34) Amarego, W. F. L.; Chai, C. L. L. Purification of Laboratory Chemicals, 5th ed.; Butterworth-Heinemann: Amsterdam, 2003.

(35) Kilah, N. L.; Weir, M. L.; Wild, S. B. Dalton Trans. 2008, 24802486.

(36) Kamai, G. Ber. Dtsch. Chem. Ges. 1935, 68B, 1893-1898.

(37) Cragoe, E. J.; Andres, R. J.; Coles, R. F.; Elpern, B.; Morgan, J. F.; Hamilton, C. S. J. Am. Chem. Soc. 1947, 69, 925-926. 
$\left(600 \mathrm{MHz}, \mathrm{CDCl}_{3}\right): \delta 2.74\left(\mathrm{dd}, J=14.3,3.3 \mathrm{~Hz}, 1 \mathrm{H}, \mathrm{H} 1_{e q}\right), 2.80$ (dd, $J=16.8,12.0 \mathrm{~Hz}, 1 \mathrm{H}, \mathrm{H} 2_{\text {eq }}$ ), 2.84 (dd, $J=14.3,14.3 \mathrm{~Hz}$, $1 \mathrm{H}, \mathrm{H} 1_{a x}$ ), 3.01 (d, $J=12.0 \mathrm{~Hz}, 1 \mathrm{H}, \mathrm{H} 2_{a x}$ ), 3.44 (s, 3H, H20) 4.60 (d, $J=11.4 \mathrm{~Hz}, 1 \mathrm{H}, \mathrm{H} 19 \mathrm{a}), 4.87$ (dd, $J=10.5,2.7 \mathrm{~Hz}, 1 \mathrm{H}, \mathrm{H} 19 \mathrm{~b})$, $6.81(\mathrm{dd}, J=6.6,3.0 \mathrm{~Hz}, 1 \mathrm{H}, \mathrm{H} 15), 6.82(\mathrm{~d}, J=8.4 \mathrm{~Hz}, 1 \mathrm{H}, \mathrm{H} 3)$, 7.08 (dd, $J=8.1,6.9 \mathrm{~Hz}, 1 \mathrm{H}, \mathrm{H} 16), 7.21-7.26$ (br m, 3H, H7, H8, H13), 7.30 (d, $J=8.4 \mathrm{~Hz}, 1 \mathrm{H}, \mathrm{H} 14), 7.33$ (dd, $J=8.4,8.4$ $\mathrm{Hz}, 1 \mathrm{H}, \mathrm{H} 17$ ), 7.42 (dd, $J=8.1,6.9 \mathrm{~Hz}, 2 \mathrm{H}, \mathrm{H6}, \mathrm{H} 12), 7.45$ (dd, $J=7.5,3.9 \mathrm{~Hz}, 1 \mathrm{H}, \mathrm{H} 18), 7.66$ (d, $J=8.4 \mathrm{~Hz}, 1 \mathrm{H}, \mathrm{H} 9), 7.71$ (d, $J=7.8 \mathrm{~Hz}, 1 \mathrm{H}, \mathrm{H} 4), 7.89$ (d, $J=8.4 \mathrm{~Hz}, 1 \mathrm{H}, \mathrm{H} 5), 7.92$ (d, $J=$ $8.4 \mathrm{~Hz}, 1 \mathrm{H}, \mathrm{H} 11), 7.93$ (d, $J=8.4 \mathrm{~Hz}, 1 \mathrm{H}, \mathrm{H} 10) .{ }^{31} \mathrm{P}\left\{{ }^{1} \mathrm{H}\right\} \mathrm{NMR}$ $\left(242.9 \mathrm{MHz}, \mathrm{CDCl}_{3}\right): \delta-9.45$. EI-MS: $\mathrm{m} / z$ (relative intensity) 432.2 amu $\left([\mathrm{M}]^{+}, 100 \%\right)$.

$\left(\mathrm{a} R_{\mathrm{P}}, S_{\mathrm{As}}\right)-\{[4-(2-M e t h o x y m e t h y l) p h e n y l]-4,5-d i h y d r o-3 H$-dinaphtho[2,1-c;1', $\left.2^{\prime}-e\right]$ phosphepine $\}$ methylphenylarsenium Hexafluorophosphate Hemidichloromethane Hemidiethyl Ether, $\left(\mathbf{a}_{\mathbf{P}}\right.$

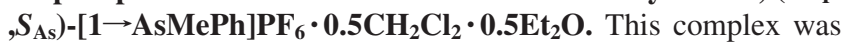
prepared by treatment of a solution $\left(\mathrm{a} R_{\mathrm{P}}\right)-\mathbf{1}(3.00 \mathrm{~g}, 6.94 \mathrm{mmol})$ and iodomethylphenylarsine $(1.94 \mathrm{~g}, 6.6 \mathrm{mmol})$ in dichloromethane $(100 \mathrm{~mL})$ with a solution of potassium hexafluorophosphate $(4.97$ $\mathrm{g}, 27 \mathrm{mmol})$ in water $(100 \mathrm{~mL})$ according to the published method. ${ }^{19}$ The product was recrystallized from dichloromethane by the addition of diethyl ether, whereupon it was isolated as colorless needles of the mixed hemisolvate: $4.1 \mathrm{~g}$ (75\%); mp 154.5-159.0 ${ }^{\circ} \mathrm{C} ;[\alpha]_{\mathrm{D}}^{25}-53.1\left(c \quad 1.0, \mathrm{CH}_{2} \mathrm{Cl}_{2}\right)$. Anal. Calcd for $\mathrm{C}_{37} \mathrm{H}_{33} \mathrm{As}-$ $\mathrm{F}_{6} \mathrm{OP}_{2} \cdot 0.5 \mathrm{CH}_{2} \mathrm{Cl}_{2} \cdot 0.5 \mathrm{C}_{4} \mathrm{H}_{10} \mathrm{O}: \mathrm{C}, 57.6, \mathrm{H}, 4.8$. Found: $\mathrm{C}, 57.8, \mathrm{H}$, 4.5. ${ }^{1} \mathrm{H}$ NMR $\left(500 \mathrm{MHz}, \mathrm{CD}_{2} \mathrm{Cl}_{2}, 24{ }^{\circ} \mathrm{C}\right): \delta 1.15(\mathrm{t}, J=6.9 \mathrm{~Hz}$, $3 \mathrm{H}, \mathrm{CH}_{3}, \mathrm{Et}_{2} \mathrm{O}$ ) 1.39 (s, 3H, H21), 2.50 (br s, $1 \mathrm{H}, \mathrm{H} 1_{a x}$ ), 3.43 (q, $\left.J=6.9 \mathrm{~Hz}, 2 \mathrm{H}, \mathrm{CH}_{2}, \mathrm{Et}_{2} \mathrm{O}\right) 3.57\left(\mathrm{dd}, J=17.3,13.8 \mathrm{~Hz}, 1 \mathrm{H}, \mathrm{H} 2_{a x}\right.$ ), 3.58 (br s, $1 \mathrm{H}, \mathrm{H} 1_{e q}$ ), 3.71 (s, $3 \mathrm{H}, \mathrm{H} 20$ ), 3.95 (dd, $J=13.8,7.8$ $\left.\mathrm{Hz}, 1 \mathrm{H}, \mathrm{H} 2_{e q}\right), 4.49$ (d, $\left.J=12.8 \mathrm{~Hz}, 1 \mathrm{H}, \mathrm{H} 19 \mathrm{a}\right), 4.59$ (d, $J=12.8$ $\mathrm{Hz}, 1 \mathrm{H}, \mathrm{H} 19 \mathrm{~b}$ ), 5.33 (s, $1 \mathrm{H}, \mathrm{CH}_{2}, \mathrm{CH}_{2} \mathrm{Cl}_{2}$ ) 7.04-7.10 (br m, 4H, H22-H26), $7.06(\mathrm{~d}, J=8.0 \mathrm{~Hz}, 1 \mathrm{H}, \mathrm{H} 14), 7.13(\mathrm{~d}, J=8.5 \mathrm{~Hz}$, 1H, H8), 7.23 (m, 2H, H22-H26), 7.25 (ddd, $J=8.5,7.0,1.5 \mathrm{~Hz}$, $1 \mathrm{H}, \mathrm{H} 7), 7.29$ (ddd, $J=8.3,7.0,1.3 \mathrm{~Hz}, 1 \mathrm{H}, \mathrm{H} 13), 7.46(\mathrm{dd}, J=$ 8.0, 8.0 Hz, 1H, H6), 7.49 (dd, $J=8.8,3.3 \mathrm{~Hz}, 1 \mathrm{H}, \mathrm{H} 3$ ), 7.49 (d, $J=8.5 \mathrm{~Hz}, 1 \mathrm{H}, \mathrm{H} 18$ ), 7.61 (dddd, $J=8.3,6.8,1.3,1.3 \mathrm{~Hz}, 1 \mathrm{H}$, H12), 7.66-7.72 (br m, 2H, H16, H17), 7.77 (br s, 1H, H9), 7.86 $(\mathrm{d}, J=8.5 \mathrm{~Hz}, 1 \mathrm{H}, \mathrm{H} 4), 7.87$ (d, $J=7.0 \mathrm{~Hz}, 1 \mathrm{H}, \mathrm{H} 5), 7.96$ (br s, $1 \mathrm{H}, \mathrm{H} 15), 8.13$ (d, $J=8.0 \mathrm{~Hz}, 1 \mathrm{H}, \mathrm{H} 11), 8.27$ (d, $J=8.0 \mathrm{~Hz}, 1 \mathrm{H}$, H10). ${ }^{31} \mathrm{P}\left\{{ }^{1} \mathrm{H}\right\}$ NMR $\left(202.42 \mathrm{MHz}, \mathrm{CD}_{2} \mathrm{Cl}_{2},-95^{\circ} \mathrm{C}\right): \delta 40.28(\mathrm{br}$ s, minor, 3\%), 38.81 (s, major, 97\%), -144.14 (sept, ${ }^{1} J_{\mathrm{PF}}=712.5$ $\left.\mathrm{Hz}, \mathrm{PF}_{6}\right)$. ESI-MS $\left(\mathrm{CH}_{3} \mathrm{OH}\right): \mathrm{m} / z$ $599.1\left(\left[\mathrm{M}-\mathrm{PF}_{6}\right]^{+}, 100 \%\right), 167.0$ $\left([\mathrm{MePhAs}]^{+}, 51 \%\right), 433.2 \mathrm{amu}\left([\mathbf{1}+\mathrm{H}]^{+}, 27 \%\right)$. Crystals of $\left(\mathrm{a} R_{\mathrm{P}}, S_{\mathrm{As}}\right)-\left[1 \rightarrow \mathrm{AsMePh}_{\mathrm{PF}} \cdot 0.3 \mathrm{Et}_{2} \mathrm{O} \cdot 0.26 \mathrm{CH}_{2} \mathrm{Cl}_{2}\right.$ suitable for $\mathrm{X}$-ray crystallography were grown by slow diffusion of diethyl ether into a solution of the salt in dichloromethane.

$\left(\mathrm{a} R_{\mathrm{P}}, S_{\mathrm{As}}\right)$ - $\{4-\mathrm{Phenyl}-4,5$-dihydro-3H-dinaphtho[2,1-c;1',2'-e]phosphepine $\}$ methylphenylarsenium Hexafluorophosphate, $\left(a R_{\mathrm{P}}\right.$ ,$\left.S_{\mathrm{As}}\right) /\left(\mathrm{a} \boldsymbol{R}_{\mathrm{P}}, \boldsymbol{S}_{\mathrm{As}}\right)$-[5 $\left.\rightarrow \mathrm{AsMePh}\right] \mathbf{P F}_{6}$. This complex was prepared from $\left(\mathrm{a} R_{\mathrm{P}}\right)-5(0.91 \mathrm{~g}, 2.34 \mathrm{mmol})$, iodomethylphenylarsine (0.62 g, 2.11 $\mathrm{mmol})$, and potassium hexafluorophosphate $(1.94 \mathrm{~g}, 10.5 \mathrm{mmol})$ in dichloromethane-water by the above method. Yield: $1.05 \mathrm{~g}$ (71\%); $\mathrm{mp} 248-249^{\circ} \mathrm{C} ;[\alpha]+153.5$ (c 1.0, acetone). Anal. Calcd for $\mathrm{C}_{36} \mathrm{H}_{30} \mathrm{AsF}_{6} \mathrm{P}: \mathrm{C}, 60.0 ; \mathrm{H}, 4.2$. Found: $\mathrm{C}, 59.8 ; \mathrm{H}, 4.1 .{ }^{1} \mathrm{H}$ NMR $\left(300 \mathrm{MHz}, \mathrm{CDCl}_{3}\right.$ ): $\delta 1.64$ (br s, 3H, $\mathrm{AsCH}_{3}$ ), 3.29-3.51 (br m, $2 \mathrm{H}, \mathrm{PCH}_{2}$ ), 3.68 (br, $1 \mathrm{H}, \mathrm{PCH}_{2}$ ), 3.89 (br, $\left.1 \mathrm{H}, \mathrm{PCH}_{2}\right), 7.11-8.21$ (br m, 22H, ArH). ${ }^{31} \mathrm{P}\left\{{ }^{1} \mathrm{H}\right\}$ NMR (121.4 MHz, $\mathrm{CD}_{2} \mathrm{Cl}_{2}, 24{ }^{\circ} \mathrm{C}$ ): $\delta$ $36.5(\mathrm{~s}),-143.2\left(\mathrm{sept},{ }^{1} J_{\mathrm{PF}}=710.9 \mathrm{~Hz}, \mathrm{PF}_{6}\right) ;\left(-78{ }^{\circ} \mathrm{C}\right): \delta 37.7$ (major, 57.5\%), $\delta 38.7$ (minor, 42.5\%), -143.2 (sept, ${ }^{1} J_{\mathrm{PF}}=710.9$ $\left.\mathrm{Hz}, \mathrm{PF}_{6}\right)$. ESI-MS (MeCN): $m / z$ 554.9 amu ([M - $\left.\left.\mathrm{PF}_{6}\right]^{+}, 13 \%\right)$.

$( \pm)$-(n-Butyl)methylphenylarsine, $( \pm)$-2. $n$-Butyllithium in hexanes (1.5 M, $21.0 \mathrm{~mL}, 31.5 \mathrm{mmol})$ was slowly added to a solution of chloromethylphenylarsine $(6.31 \mathrm{~g}, 31.5 \mathrm{mmol})$ in THF $(50 \mathrm{~mL})$ at $0{ }^{\circ} \mathrm{C}$. Following the addition, the reaction mixture was stirred for $10 \mathrm{~min}$, and then the solvent was removed under reduced pressure. Diethyl ether $(50 \mathrm{~mL})$ was added, and unreacted $n$-BuLi was quenched with water $(50 \mathrm{~mL})$. The aqueous phase was extracted with additional diethyl ether $(4 \times 20 \mathrm{~mL})$, and the combined organic fraction was dried over $\mathrm{MgSO}_{4}$. The dried solution was filtered, and the product was purified by distillation: $6.39 \mathrm{~g}(92 \%)$; bp 55-62 ${ }^{\circ} \mathrm{C}(0.8 \mathrm{mmHg})$. Anal. Calcd for $\mathrm{C}_{11} \mathrm{H}_{17} \mathrm{As}$ : C, 58.9; H 7.6. Found: $\mathrm{C}, 59.0 ; \mathrm{H} 7.5 .{ }^{1} \mathrm{H}$ NMR $\left(300 \mathrm{MHz}, \mathrm{CDCl}_{3}\right): \delta 0.87\left(\mathrm{t},{ }^{3} \mathrm{~J}_{\mathrm{HH}}=7.1\right.$ $\left.\mathrm{Hz}, 3 \mathrm{H}, \mathrm{CH}_{3}\right), 1.18\left(\mathrm{~s}, 3 \mathrm{H}, \mathrm{AsCH}_{3}\right), 1.31-1.48(\mathrm{~m}, 4 \mathrm{H}$, $\left.\mathrm{CH}_{2} \mathrm{CH}_{2} \mathrm{CH}_{3}\right), 1.58-1.75\left(\mathrm{~m}, 2 \mathrm{H}, \mathrm{AsCH}_{2}\right), 7.25-7.50(\mathrm{~m}, 5 \mathrm{H}$, $\mathrm{ArH})$. EI-MS: $m / z 224\left([\mathrm{M}]^{+}\right), 167$ amu $\left([\mathrm{M}-(n-\mathrm{Bu})]^{+}\right)$.

$\left(S_{\mathrm{C}}, R_{\mathrm{As}}\right)$-trans-[(n-Butyl)methylphenylarsine]chloro[1-[1-(dimethylamino)ethyl]naphthalenyl- $C, N]$ palladium(II), $\left(S_{\mathrm{C}}, R_{\mathrm{As}}\right)-4$. Two equivalents of $( \pm)-2(0.31 \mathrm{~g}, 1.40 \mathrm{mmol})$ in dichloromethane $(20 \mathrm{~mL})$ were added to a solution of $\left(S_{\mathrm{C}}, S_{\mathrm{C}}\right)-\mathbf{3} \cdot \mathrm{CH}_{2} \mathrm{Cl}_{2}(0.47 \mathrm{~g}$, $7.0 \mathrm{mmol})$ in the same solvent $(20 \mathrm{~mL})$. The solution was stirred for $30 \mathrm{~min}$. The solvent was removed from the reaction mixture under reduced pressure to leave a yellow glassy solid that was crystallized from wet acetone. After the third recrystallization, configurationally pure $\left(S_{\mathrm{C}}, R_{\mathrm{As}}\right)-\mathbf{4}$ was isolated as pale yellow needles; mp 203-205 ${ }^{\circ} \mathrm{C} ;[\alpha]=+104.8$ (c 1.0, $\left.\mathrm{CH}_{2} \mathrm{Cl}_{2}\right)$. Anal. Calcd for $\mathrm{C}_{25} \mathrm{H}_{33}$ AsCINPd: C, 53.2; H, 5.9. Found: C, 53.6; H, 6.0. ${ }^{1} \mathrm{H} \mathrm{NMR}\left(300 \mathrm{MHz}, \mathrm{CDCl}_{3}\right): \delta 0.74\left(\mathrm{t},{ }^{3} J_{\mathrm{HH}}=7.3 \mathrm{~Hz}, 3 \mathrm{H}\right.$, $\left.\left(\mathrm{CH}_{2}\right)_{3} \mathrm{CH}_{3}\right), 1.22-1.47\left(\mathrm{~m}, 4 \mathrm{H}, \mathrm{CH}_{2} \mathrm{CH}_{2} \mathrm{CH}_{2} \mathrm{CH}_{3}\right), 1.83(\mathrm{~s}, 3 \mathrm{H}$, $\left.\mathrm{AsCH}_{3}\right), 1.97\left(\mathrm{~d},{ }^{3} \mathrm{~J}_{\mathrm{HH}}=6.3 \mathrm{~Hz}, 3 \mathrm{H}, \mathrm{CHCH}_{3}\right), 2.31-2.19(\mathrm{~m}, 2 \mathrm{H}$, $\left.\mathrm{AsCH}_{2}\right), 2.76\left(\mathrm{~s}, 3 \mathrm{H}, \mathrm{NCH}_{3}\right), 2.95\left(\mathrm{~s}, 3 \mathrm{H}, \mathrm{NCH}_{3}\right), 4.31\left(\mathrm{q},{ }^{3} J_{\mathrm{HH}}=\right.$ $\left.4.3 \mathrm{~Hz}, 1 \mathrm{H}, \mathrm{CHCH}_{3}\right), 6.78-7.90(\mathrm{~m}, 11 \mathrm{H}, \mathrm{ArH})$. EI-MS: m/z 564 amu $\left([\mathrm{M}]^{+}\right)$. Crystals of $\left(S_{\mathrm{C}}, R_{\mathrm{As}}\right)-4$ suitable for X-ray crystallography were grown by slow cooling of a hot acetone solution of the complex.

Asymmetric Synthesis. To a solution of $\left(\mathrm{a} R_{\mathrm{P}}, S_{\mathrm{As}}\right)-[\mathbf{1} \rightarrow \mathrm{As}-$ $\mathrm{MePh}] \mathrm{PF}_{6} \cdot 0.5 \mathrm{CH}_{2} \mathrm{Cl}_{2} \cdot 0.5 \mathrm{Et}_{2} \mathrm{O}$ (ca. $10 \mu \mathrm{mol}$ ) in dichloromethane $\left(1 \mathrm{~mL}\right.$ ) at $-95^{\circ} \mathrm{C}$ was added $1.0-1.1$ equiv of $n$-butyllithium (ca. 1.4 $\mathrm{M}$ in hexanes). The mixture was stirred for $5 \mathrm{~min}$ and then quenched with water $(10 \mu \mathrm{L})$. The cooling bath was removed, and once the mixture had warmed to room temperature, a suspension of $\left(S_{\mathrm{C}}, S_{\mathrm{C}}\right)-\mathbf{3} \cdot \mathrm{CH}_{2} \mathrm{Cl}_{2}$ (1.3 equiv) in dichloromethane was added. After a further $15 \mathrm{~min}$, the solution was concentrated to a small volume and transferred to a short silica/dichloromethane column. The first fraction (excess $\left(S_{\mathrm{C}}, S_{\mathrm{C}}\right)$-3) was eluted with neat dichloromethane; the second fraction (mixture of $\left(S_{\mathrm{C}}, R_{\mathrm{As}}\right) /\left(S_{\mathrm{C}}, S_{\mathrm{As}}\right)-\mathbf{4}$ and corresponding complex of $\left.\left(\mathrm{a} R_{\mathrm{P}}\right)-\mathbf{1}\right)$ was eluted with $10 \%$ diethyl ether-dichloromethane. After evaporation of the solvent from the second fraction, the residue was dissolved in chloroform- $d$ and the enantioselectivity of the arsine synthesis was determined by integration of the $\mathrm{AsCH}_{2} \mathrm{CH}_{2} \mathrm{CH}_{2} \mathrm{CH}_{3}$ and $\mathrm{AsCH}_{3}$ resonances for $\left(S_{\mathrm{C}}, R_{\mathrm{As}}\right) /\left(S_{\mathrm{C}} S_{\mathrm{As}}\right)-\mathbf{4}$ in the ${ }^{1} \mathrm{H}$ NMR spectrum.

X-ray Crystallography. X-ray diffraction data were collected at $200 \mathrm{~K}$ on a Nonius Kappa CCD diffractometer. Data were processed with the Denzo/Scalepack software ${ }^{38}$ with absorption corrections ${ }^{39}$ being applied. The structures were solved by direct methods with the program SIR92. ${ }^{40}$ Non-hydrogen atoms within the cation were refined anisotropically, and hydrogen atoms were placed at idealized positions. Full-matrix least-squares refinement on $F$ was performed with the CRYSTALS program ${ }^{41}$ for $\left(\mathrm{a} R_{\mathrm{P}}, S_{\mathrm{As}}\right)$ $\left[1 \rightarrow \mathrm{AsMePh}_{\mathrm{PF}} \cdot 0.26 \mathrm{CH}_{2} \mathrm{Cl}_{2} \cdot 0.37 \mathrm{Et}_{2} \mathrm{O}\right.$ and the texSan program ${ }^{42}$ for $\left(\mathrm{a} R_{\mathrm{P}}, S_{\mathrm{As}}\right)-4$. The absolute configuration of the complex $\left(\mathrm{a} R_{\mathrm{P}}, S_{\mathrm{As}}\right)$ $\left[1 \rightarrow \mathrm{AsMePh}_{\mathrm{PF}} \cdot 0.26 \mathrm{CH}_{2} \mathrm{Cl}_{2} \cdot 0.37 \mathrm{Et}_{2} \mathrm{O}\right.$ was determined by refinement of a Flack parameter, final value -0.009 (11), and was consistent with the known configuration of the phosphepine $\left(\mathrm{a} R_{\mathrm{P}}\right)$; 326.

(38) Otwinowski, Z.; Minor, W. Methods Enzymol. 1996, 276, 307-

(39) Coppens, P. In Crystallographic Computing; Ahmed, F. R.; Hall, S. R., Huber, C. P., Eds.; Munksgaard: Copenhagen, 1970; pp 255-270. (40) Altomare, A.; Cascarano, G.; Giacovazzo, C.; Guagliardi, A.; Burla, M. C.; Polidori, G.; Camalli, M. J. Appl. Crystallogr. 1994, $27,435$.

(41) Betteridge, P. W.; Carruthers, J. R.; Cooper, R. I.; Prout, K.; Watlan, D. J. J. Appl. Crystallogr. 2003, 36, 1487.

(42) teXsan: Single-Crystal Structure Analysis Package, version 1.8; Molecular Structure Corporation: The Woodlands, TX, 1997. 
for $\left(\mathrm{a} R_{\mathrm{P}}, S_{\mathrm{As}}\right)-\mathbf{4}$, refinement of a Flack parameter gave the value $0.00010(8)$, which was consistent with the known configuration of the carbon stereocenter of the orthometalated amine ligand of the complex $(S)$.

Crystal data for $\left(\mathrm{a} R_{\mathrm{P}}, S_{\mathrm{As}}\right)-[\mathbf{1} \rightarrow \mathrm{AsMePh}] \mathrm{PF}_{6} \cdot 0.26 \mathrm{CH}_{2} \mathrm{Cl}_{2} \cdot$ $0.37 \mathrm{Et}_{2} \mathrm{O}, \mathrm{C}_{37} \mathrm{H}_{33} \mathrm{~F}_{6} \mathrm{AsOP}_{2} \cdot 0.26 \mathrm{CH}_{2} \mathrm{Cl}_{2} \cdot 0.37 \mathrm{C}_{4} \mathrm{H}_{10} \mathrm{O}: M=794.34$, hexagonal, space group $P 6_{1} 22, a=16.4233(2) \AA, c=47.0990(4)$ $\AA, V=11003.1 \AA^{3}, Z=12, D=1.438 \mathrm{~g} \mathrm{~cm}^{-3}, \mu($ Mo K $\alpha)=$ $1.115 \mathrm{~mm}^{-1}, T=200 \mathrm{~K}$, colorless needle, crystal size $0.50 \times 0.16$ $\times 0.16 \mathrm{~mm}, 6473$ independent reflections, $F$ refinement, $R=$ $0.0366, w R=0.0386,4312$ independent observed reflections $(I>$ $2.00 \sigma(I)), 451$ parameters.

Crystal data for $\left(S_{\mathrm{C}}, R_{\mathrm{As}}\right)-\mathbf{4}, \mathrm{C}_{25} \mathrm{H}_{23} \mathrm{AsClNPd}: M=564.3$, orthorhombic, $P 2{ }_{1} 2{ }_{1} 2{ }_{1}, a=9.9468(1) \AA, b=13.5370(2) \AA, c=$ 18.6809(2) $\AA, V=2515.38(4) \AA^{3}, Z=4, D=1.49 \mathrm{~g} \mathrm{~cm}^{-3}, \mu(\mathrm{Mo}$ $\mathrm{K} \alpha)=2.161 \mathrm{~mm}^{-1}, T=200 \mathrm{~K}$, pale yellow needle, crystal size $0.25 \times 0.11 \times 0.10 \mathrm{~mm}, 7346$ independent reflections, $F$ refinement, $R=0.0309, R_{\mathrm{w}}=0.0321,6019$ independent observed reflections $(I>2.00 \sigma(I)), 269$ parameters.

Computational Procedures. Density functional calculations ${ }^{43}$ were performed using the hybrid functional B3LYP in the Gaussian 03 program. $^{44}$ B3LYP provides accurate results in geometry optimizations ${ }^{45}$ and performs well in geometry optimizations and frequency calculations when compared with high-level (coupled cluster) calculations for computationally demanding situations, such as radical reactions. ${ }^{46}$ Geometries were obtained at the B3LYP/6-

(43) Koch, W.; Holthausen, M. C. A Chemist's Guide to Density Functional Theory; Wiley-VCH: Weinheim, 2000.

(44) Frisch, M. J.; Trucks, G. W.; Schlegel, H. B.; Scuseria, G. E.; Robb, M. A.; Cheeseman, J. R. ; Montgomery, J. A., Jr.; Vreven, T.; Kudin, K. N. ; Burant, J. C.; Millam, J. M.; Iyengar, S. S.; Tomasi, J.; Barone, V.; Mennucci, B.; Cossi, M.; Scalmani, G.; Rega, N.; Petersson, G. A.; Nakatsuji, H.; Hada, M.; Ehara, M.; Toyota, K.; Fukuda, R.; Hasegawa, J.; Ishida, M.; Nakajima, T.; Honda, Y.; Kitao, O.; Nakai, H.; Klene, M.; Li, X.; Knox, J. E.; Hratchian, H. P.; Cross, J. B.; Bakken, V.; Adamo, C.; Jaramillo, J.; Gomperts, R.; Stratmann, R. E.; Yazyev, O.; Austin, A. J.; Cammi, R.; Pomelli, C.; Ochterski, J. W.; Ayala, P. Y.; Morokuma, K.; Voth, G. A.; Salvador, P.; Dannenberg, J. J.; Zakrzewski, V. G.; Dapprich, S.; Daniels, A. D.; Strain, M. C.; Farkas, O.; Malick, D. K.; Rabuck, A. D.; Raghavachari, K.; Foresman, J. B.; Ortiz, J. V.; Cui, Q.; Baboul, A. G.; Clifford, S.; Cioslowski, J.; Stefanov, B. B.; Liu, G.; Liashenko, A.; Piskorz, P.; Komaromi, I.; Martin, R. L.; Fox, D. J.; Keith, T.; Al-Laham, M. A.; Peng, C. Y.; Nanayakkara, A.; Challacombe, M.; Gill, P. M. W.; Johnson, B.; Chen, W.; Wong, M. W.; Gonzalez, C.; Pople, J. A. GAUSSIAN 03, Revision B.03; Gaussian Inc.: Wallingford, CT, 2004.

(45) Kohn, W.; Becke, A. D.; Parr, R. G. J. Phys. Chem. 1996, 100, 12974-12980.

(46) See for example: (a) Coote, M. L.; Wood, G. P. F.; Radom, L. J. Phys. Chem. A 2002, 106, 12124-12138. (b) Gómez-Baldera, R.; Coote, M. L.; Henry, D. J.; Radom, L. J. Phys. Chem. A 2004, 108, 2874-2883.

(47) Dunning, T. H., Jr.; Hay, P. J. In Modern Theoretical Chemistry; Schaefer, H. F., III, Ed.; Plenum: New York, 1976; Vol. 3, pp 1-28.
$31 G(d)$ level of theory using the LANL2DZ ${ }^{48}$ effective core potential for the inner-shell electrons on arsenic. In order to identify all relevant conformations, full geometry optimizations were carried out for 72 different starting structures corresponding to combinations of rotations about the $\mathrm{P}-\mathrm{As}, \mathrm{P}-\mathrm{C}_{6} \mathrm{H}_{5}, 2-\left(\mathrm{CH}_{3} \mathrm{OCH}_{2}\right)-\mathrm{C}_{6} \mathrm{H}_{4} \mathrm{P}$, and $\mathrm{CH}_{2}-\mathrm{OMe}$ bonds in both diastereomers (see Figure $\mathrm{S} 1$ of the Supporting Information for an illustration of these bonds). Complete geometries and total energies for all species are given as Gaussian archive entries in the Supporting Information.

On the basis of the initial conformation search, distinct species within $12 \mathrm{~kJ} \mathrm{~mol}^{-1}$ of the global minimum energy structure were selected for further investigation. For the selected species, frequencies were calculated at the B3LYP/6-31G(d) level of theory and scaled by the appropriate scale factors, ${ }^{48}$ and improved energies were also calculated at the B3LYP/6-311+G(3df,2p) level of theory. The data were then used to obtain free energies at $-95{ }^{\circ} \mathrm{C}$ in conjunction with the standard textbook formulas for the statistical thermodynamics of an ideal gas under the harmonic oscillator/rigid rotor approximation. These free energies were then used to calculate diastereomeric ratios for $\left(\mathrm{a} R_{\mathrm{P}}, R_{\mathrm{As}}\right) /\left(\mathrm{a} R_{\mathrm{P}}, S_{\mathrm{As}}\right)-[6 \rightarrow \mathrm{AsMePh}]^{+}$by application of the Boltzmann distribution law as given by the equation $n_{\mathrm{i}} / N=e\left(-\varepsilon_{\mathrm{i}} / k_{\mathrm{B}} T\right) / \Sigma_{\mathrm{i}} e\left(-\varepsilon_{\mathrm{i}} / k_{\mathrm{B}} T\right)$, where $n_{i}=$ number of molecules in the $i$ th energy state, $N=$ total number of molecules, $\varepsilon_{I}=$ free energy of state $I, k_{\mathrm{B}}=$ Boltzmann constant, and $T=$ temperature in Kelvin. ${ }^{33}$ The correct application of this equation requires use of the molecular free energies of all 72 species, but this was impractical for the large molecules under consideration. Accordingly, conformers of the molecule with non-zero-pointenergy corrected energies within $12 \mathrm{~kJ} \mathrm{~mol}^{-1}$ of the global minimum at $0 \mathrm{~K}$ were selected for the Boltzmann analysis. Higherenergy conformers were expected to be present in negligible concentrations $\left(<0.03 \%\right.$ at $\left.-95{ }^{\circ} \mathrm{C}\right)$.

Acknowledgment. This work was supported by the Australian Research Council, the ANU Supercomputing Facility, and the Australian Partnership for Advanced Computing.

Supporting Information Available: B3LYP/6-31G(d)-optimized geometries in the form of Gaussian archive entries and corresponding B3LYP/6-311+G(3df,2p) improved energies and associated thermodynamic data at $178 \mathrm{~K}$ for the low-energy conformers. Crystallographic data for the two complexes (CIF). This material is available free of charge via the Internet at http://pubs.acs.org.

\section{OM8006272}

(48) Scott, A. P.; Radom, L. J. Phys. Chem. 1996, 100, 16502-16513. 